\title{
DISTRIBUIÇÃO DA CONTAMINAÇÃO COM AFLATOXINAS NOS TIPOS DE GRÃOS DE AMENDOIM (Arachis hypogaea L.), DEFINIDOS PELA CLASSIFICAÇÃO OFICIAL DO BRASIL
}

\author{
ANA HELENA OLIVA STEFANOVITZ \\ Bióloga
}

Orientador: Prof. Dr. HOMERO FONSECA

Dissertação apresentada à Escola

Superior de Agricultura "Luiz de Queiroz", da Universidade de São Paulo, para obtenção do título de Mestre em Ciências, Área de Concentração: Ciência e Tecnologia de Alimentos.

$P \mid R A C I C A B A$

Estado de São Paulo - Brasil

Outubro - 1996 
Dados Internacionais de Catalogação na Publicação (CIP)

DIVISÃO DE BIBLIOTECA E DOCUMENTAÇÃO - Campus "Luiz de Queiroz"/USP

Stefanovitz, Ana Helena Oliva

Distribuição da contaminação com aflatoxinas nos tipos de grăos de amendoim (Arachis hypogaea L.), definidos pela classificação oficial do Brasil / Ana Helena Oliva Stefanovitz. Piracicaba, 1996.

56 p. : ii.

Dissertação (mestrado) - - Escola Superior de Agricultura Luiz de Queiroz, 1996.

Bibliografia.

1. Aflatoxina em amendoim 2. Amendoim - Contaminação fungi 3. Amendoim Toxicologia I. Titulo

CDD 664.805659 


\title{
AFLATOXINAS NOS TIPOS DE GRÃOS DE AMENDOIM (Arachis hypogaea L.) DEFINIDOS PELA CLASSIFICAÇÃO OFICIAL DO BRASIL
}

\author{
ANA HELENA OLIVA STEFANOVITZ
}

Aprovada em: 04/12/1996

Comissão julgadora:

Prof. Dr. Homero Fonseca

ESALQ/USP

Prof. Dr. Claudio Rosa Gallo

ESALQ/USP

Prof. Dr. Benedito Corrêa

ICB/USP

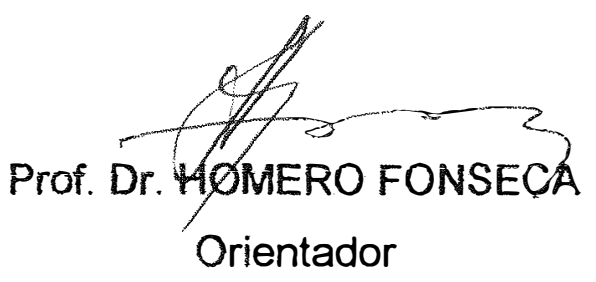


À minha mãe, Anna Maria, DEDICO

Ao Valmir Antonio Costa, OFEREÇO 


\section{AGRADECIMENTOS}

Ao Dr. Homero Fonseca, Professor do Departamento de Ciência e Tecnologia Agroindustrial da ESALQ/USP, pela orientação, sugestões e incentivo recebidos no decorrer desta pesquisa;

Aos Eng ${ }^{\text {os }}$ Agr $^{\text {os }}$ Maria Antônia Calori Domingues e Eduardo Micotti da Gloria, pela contribuição na elaboração deste projeto, bem como na discussão dos resultados preliminares;

Ao $\mathrm{Eng}^{\circ} \mathrm{Agr}^{\circ}$ Valmir Antonio Costa pelo carinho, sugestões e, principalmente, pelo grande estímulo recebido, o qual foi essencial para a realização desta pesquisa;

Ao Eng $^{\circ}$ Agr $^{\circ}$ Daniel Martins Sodero, da CATI/SP, pela orientação na classificação dos tipos de grãos de amendoim;

À Biomédica Ivani Valarini Zambello e à acadêmica Juliana Pizarro Ota, pela colaboração e amizade;

À GRANOL Indústria, Comércio e Exportação S.A. unidade de JunqueirópolisSP, na pessoa do $\mathrm{Eng}^{\circ} \mathrm{Agr}^{\circ}$ Oscar Tomio Fudo, pelo auxílio e colaboração na coleta das amostras;

À Fundação de Amparo à Pesquisa do Estado de São Paulo, pelo auxílio financeiro indispensável à realização desta pesquisa;

Ao CNPq, pela concessão de bolsa de estudo para a realização do curso; 
Às bibliotecárias Kátia Maria de Andrade Ferraz, Eliana Maria Garcia Sabino e Beatriz Helena Giongo, pela atenção dedicada à revisão da bibliografia;

Aos professores e funcionários do Departamento de Ciência e Tecnologia Agroindustrial da ESALQ/USP, pelos ensinamentos e amizade;

À minha mãe Anna Maria, que sempre acompanhou minhas atividades, pelo carinho, compreensão e dedicação em todos os momentos;

Aos colegas do Curso de Pós-Graduação, pela amizade e incentivo;

$\mathrm{E}$ a todas as pessoas que me incentivaram ou de algum modo contribuíram para execução deste projeto de pesquisa. 


\section{SUMÁRIO}

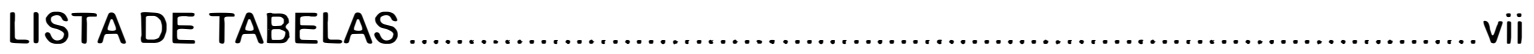

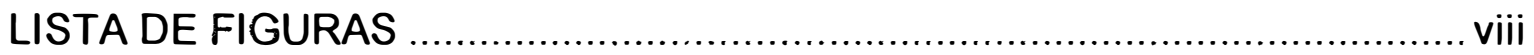

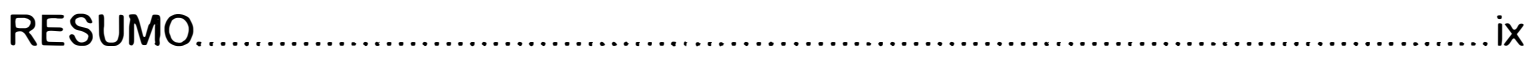

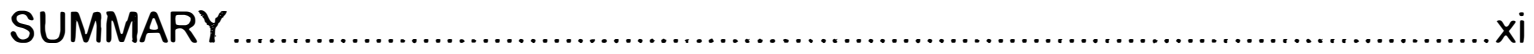

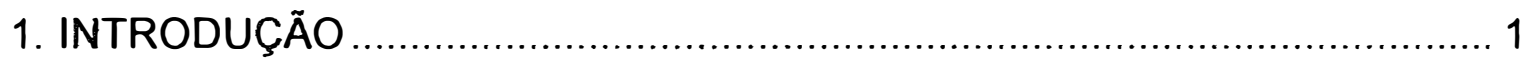

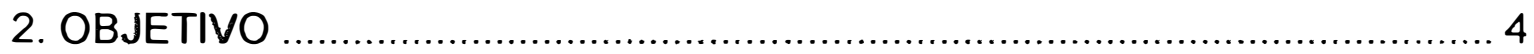

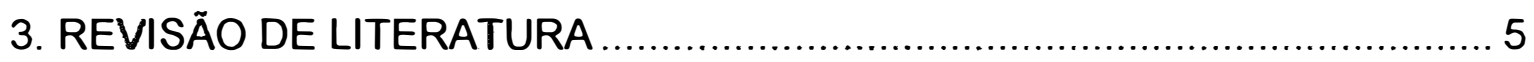

3.1. Características e efeitos tóxicos das aflatoxinas .................................. 5

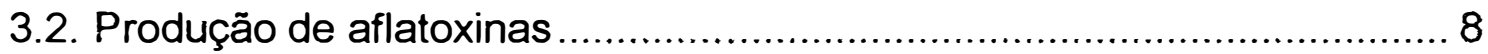

3.3. Ocorrência de aflatoxinas em amendoim no Brasil .............................. 11

3.4. Distribuição e separação dos grãos contaminados .............................. 15

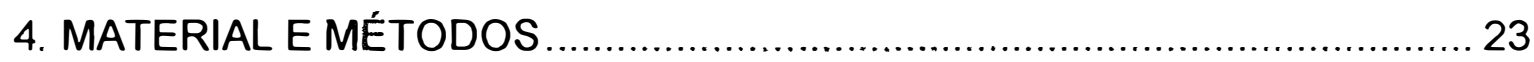

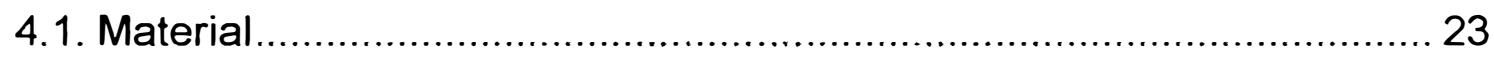

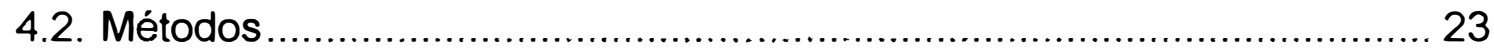

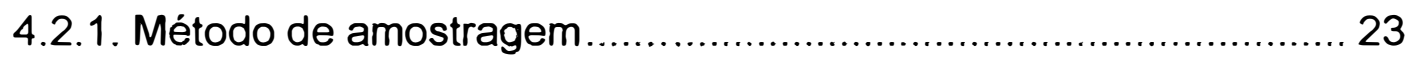

4.2.2. Determinação do teor da umidade inicial .................................. 24

4.2.3. Método de classificação dos grãos ............................................ 24

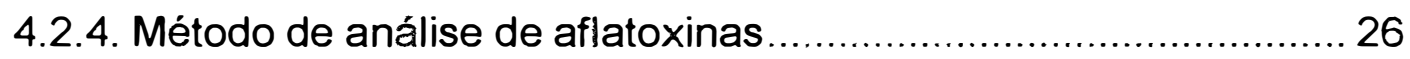

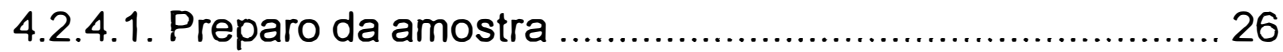

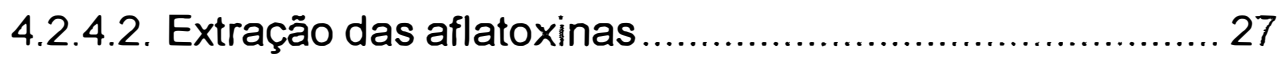


4.2.4.3. Detecção e quantificação das aflatoxinas...................... 29

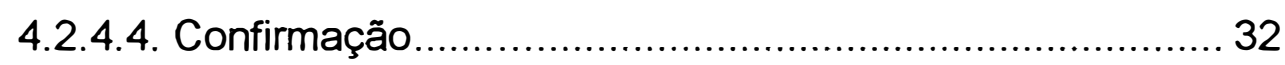

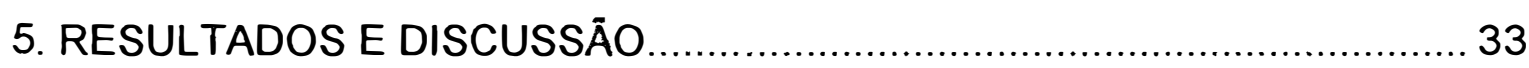

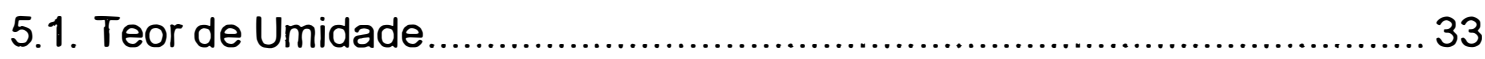

5.2. Distribuição da contaminação das aflatoxinas nos diversos tipos de

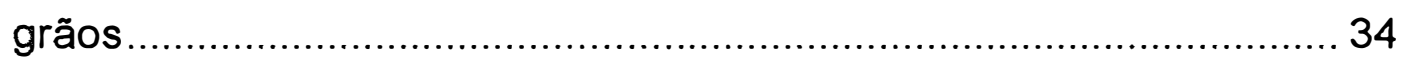

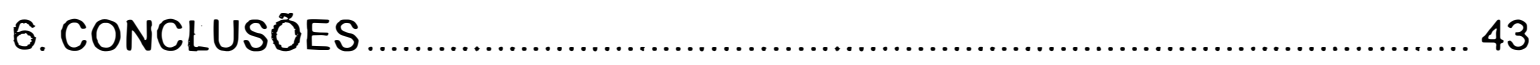

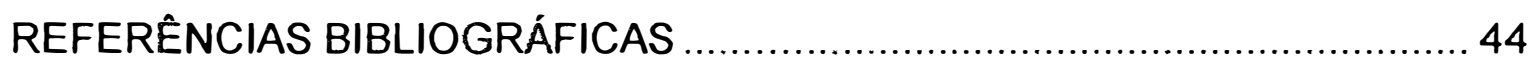




\section{LISTA DE TABELAS}

Tabela 1. Teor das aflatoxinas $B_{1}+B_{2}+G_{1}+G_{2}$, em $\mu g / k g$, nos tipos de grãos analisados em duplicata, de cada lote. 35

Tabela 2. Teores médios de aflatoxinas $\left(B_{1}+B_{2}+G_{1}+G_{2}\right)$ nos diferentes tipos de grãos de amendoim encontrados nos 9 lotes utilizados e percentagem média do peso de cada tipo.

Tabela 3. Variação da contaminação com aflatoxinas nos vários tipos de grãos. 38

Tabela 4. Teores médios de aflatoxinas $\left(B_{1}+B_{2}+G_{1}+G_{2}\right)$, média da participação na contaminação dos 9 lotes e percentagem média do peso nos diferentes tipos de grãos de amendoim. 39

Tabela 5. Teores médios de aflatoxinas $\left(B_{1}+B_{2}+G_{1}+G_{2}\right)$ nos diferentes tipos de grãos de amendoim encontrados no lote 1, sua participação na contaminação e percentagem média do peso de cada tipo 


\section{LISTA DE FIGURAS}

Figura 1. Esquema da divisão da placa de cromatografia bidirecional e disposição das aliquotas do padrão e extrato da amostra........... 31

Figura 2. Teor médio (em percentagem) da umidade das amostras de amendoim. 33

Figura 3. Valores médios de aflatoxinas $\left(B_{1}+B_{2}+G_{1}+G_{2}\right)$ nos diferentes tipos de grãos de amendoim 36 


\title{
DISTRIBUIÇÃO DA CONTAMINAÇÃO COM AFLATOXINAS NOS TIPOS DE GRÃOS DE AMENDOIM (Arachis hypogaea L.), DEFINIDOS PELA CLASSIFICAÇÃO OFICIAL DO BRASIL
}

\author{
Autor: ANA HELENA OLIVA STEFANOVITZ \\ Orientador: Prof. Dr. HOMERO FONSECA
}

\section{RESUMO}

Este trabalho visou conhecer a distribuição da contaminação, com aflatoxinas, entre os tipos de grãos de amendoim, conforme definidos pela classificação oficial do Ministério da Agricultura do Brasil (Brasil, 1981). No Brasil, a classificação oficial estabelece os seguintes tipos de amendoim: mofado, brotado, imaturo, ardido, danificado, peliculado, despeliculado, quebrado e chocho.

Foram tomados 9 lotes de amendoim descascado da variedade Tatu, sendo retirada de cada um uma amostra de $20 \mathrm{~kg}$, os quais apresentaram uma contaminação média por aflatoxinas de $1.968,28 \mu \mathrm{g} / \mathrm{kg}$. Os grãos de cada lote foram separados de acordo com a classificação oficial, e determinado o nivel de aflatoxinas, para verificar a distribuição da contaminação em cada tipo.

A contaminação poì aflatoxinas foi maior nos grãos mofados $(13.921 \mu \mathrm{g} / \mathrm{kg})$, seguido pelos grãos brotados $(7.046 \mu \mathrm{g} / \mathrm{kg})$, ardidos 
$(4.028 \mu \mathrm{g} / \mathrm{kg})$, imaturos $(3.609 \mu \mathrm{g} / \mathrm{kg})$, chochos $(1.527 \mu \mathrm{g} / \mathrm{kg})$ e danificados (760 $\mu \mathrm{g} / \mathrm{kg}$ ). Juntos, estes grãos foram responsáveis em média por $97,16 \%$ da contaminação total do lote. A segregação desses tipos de grãos pode diminuir consideravelmente a contaminação do lote e poderá tornar-se viável economicamente, se o lote não estiver altamente contaminado. 


\title{
DISTRIBUTION OF THE AFLATOXIN CONTAMINATION IN DIFFERENT TYPES OF PEANUT (Arachis hypogaea L.) KERNELS, AS DEFINED BY THE BRAZILIAN OFFICIAL CLASSIFICATION
}

\author{
Author: ANA HELENA OLIVA STEFANOVITZ \\ Adviser: Prof. Dr. HOMERO FONSECA
}

\section{SUMMARY}

This research deals with the levels of aflatoxin contamination in the different types of peanut kernels, as defined by the Brazilian Official Classification. The established types of kernels are moldy, germinated, immature, fermented, injured, with skin, without skin, broken and undeveloped.

From each 9 lots of shelled peanuts of the Tatu variety, which were known to be heavily contaminated (by previous analyses) samples of twenty-kg were taken. The kernels were separated, according to the official classification, and analyzed to check for aflatoxins distribution in each type of kernel.

The aflatoxin contamination was higher in the moldy type $(13,921 \mu \mathrm{g} / \mathrm{kg})$, followed by germinated $(7,046 \mu \mathrm{g} / \mathrm{kg})$, fermented $(4,028 \mu \mathrm{g} / \mathrm{kg})$, immature $(3,609 \mu \mathrm{g} / \mathrm{kg})$, undeveloped $(1,527 \mu \mathrm{g} / \mathrm{kg})$ and injured $(760 \mu \mathrm{g} / \mathrm{kg})$. Together, these kernels accounted for $97.16 \%$ of the total aflatoxins of the lot. 
The segregation of these types of kernels would help milling units to improve the peanut quality, provided the aflatoxin level of the lot is not excessively high. 


\section{INTRODUÇÃO}

Atualmente, o Estado de São Paulo é o principal produtor de amendoim no Brasil, não só pela maior área plantada, como também pela maior produção, sendo responsável por $80 \%$ do total produzido no país (AGRIANUAL, 1996).

A contaminação por aflatoxinas, produzidas principalmente por fungo Aspergillus flavus e $A$. parasitucus, vem acarretando constantes prejuizos aos produtores, cerealistas e indústrias alimentícias. Como conseqüência deste fato e de outras circunstâncias, como a expansão da cultura da soja no Brasil, houve uma redução significativa da área destinada ao plantio de amendoim no país. Segundo a FAO (1995), entre 1979 e 1981, a produção de amendoim no Brasil foi, em média, 433 mil toneladas por ano, enquanto que no ano de 1995 foi de 146 mil toneladas, representando uma redução de aproximadamente $66 \%$.

A contaminação do amendoim por aflatoxinas pode ocorrer durante o desenvolvimento da cultura, na fase de pós-colheita e no armazenamento. Atualmente, não existem técnicas agronômicas que permitam a colheita de um produto livre da contaminação com aflatoxinas quando as 
condições climáticas são adversas. Há, contudo, procedimentos ou práticas agrícolas que, quando aplicados desde a instalação da cultura até o armazenamento do amendoim, podem, em conjunto ou isoladamente, reduzir o nivel da contaminação com aflatoxinas.

No Estado de São Paulo, o maior volume de produção de amendoim é proveniente da safra denominada "das águas", cuja colheita ocorre nos meses de janeiro a março, período esse com elevados índices pluviométricos e temperaturas. Esta é uma situação bastante desfavorável à obtenção de amendoim adequadamente seco. Com o maior teor de umidade dos lotes, o amendoim terá maiores problemas de contaminação durante o armazenamento.

Dentro deste contexto, assume grande importância a utilização de técnicas que permitam a descontaminação dos lotes, para que tenham a somatória das aflatoxinas $B_{1}+B_{2}+G_{1}+G_{2}$ abaixo de $20 \mu \mathrm{g} / \mathrm{kg}$, como exige a nova legislação brasileira (Brasil, 1996).

Os métodos de destoxificação hoje conhecidos são, principalmente, de natureza química e física. Os métodos químicos para o amendoim têm se mostrado inviáveis, devido aos resíduos que deixam na matéria-prima e/ou modificações que provocam no alimento. Os métodos físicos são tecnicamente os mais viáveis para o amendoim e, por isso, são os mais utilizados. 
Os métodos físicos de descontaminação do amendoim utilizados atualmente têm se baseado na separação de certos tipos de grãos que compõem um lote e que apresentam maior probabilidade de estarem contaminados com aflatoxinas.

No Estado de São Paulo, as técnicas utilizadas para reduzir o nivel de contaminação de um lote são a catação manual do amendoim em esteira e a segregação por máquinas eletrônicas com fotocélula sensivel à diferença de coloração da película do grão. O conhecimento da distribuição da contaminação entre os tipos de grãos que compõem um lote, para as variedades mais plantadas no Brasil, é primordial para uma melhor utilização destas técnicas.

Atualmente, existe no País uma classificação dos tipos de grãos estabelecida pelo Ministério da Agricultura do Brasil; contudo, não há dados sobre o grau de contaminação com aflatoxinas desses diversos tipos. 


\section{OBJETIVO}

Este trabalho visou conhecer a distribuição da contaminação, com aflatoxinas, entre os tipos de grãos de amendoim, conforme definidos pela classificação oficial do Ministério da Agricultura do Brasil, para a variedade Tatu. 


\section{REVISÃO DE LITERATURA}

\subsection{Características e efeitos tóxicos das aflatoxinas}

As aflatoxinas foram identificadas no início da década de 60, após a morte, na Inglaterra, de 100 mil peruzinhos que receberam ração contendo farelo de amendoim brasileiro, contaminado com Aspergillus flavus (Blount ${ }^{1}$, citado por Goldblatt, 1969). Este acontecimento, que estimulou o interesse científico, deu origem à micotoxicologia moderna (Diener et al. 1987) e transformou as aflatoxinas em uma preocupação na área da saúde e comercial. No mundo todo, há uma crescente conscientização das sérias conseqüências que niveis elevados de aflatoxinas nos alimentos podem causar à saúde humana e dos animais (FAO, 1993).

As aflatoxinas são substâncias químicas pertencentes ao grupo das bi-furanocumarinas e diferem entre si apenas por pequenas variações em

1 Blount, W.P. Turkey "X" disease. Turkeys (Journal of the British Turkey Federation) 9(2): 52, 55-58, 61, 77. 1961. 
sua composição e estrutura molecular (Organizacion Panamericana De La Salud, 1983). Elas têm origem no metabolismo secundário de duas espécies fúngicas, Aspergillus flavus e A. parasiticus (Raper \& Fennell, 1965), além de outras espécies como Aspergillus nomius, Aspergillus niger e Penicillium puberulum (Diener \& Davis, 1969a; Saad et al.,1995).

Embora o termo aflatoxinas possa referir-se a 17 compostos, o mesmo tem sido utilizado praticamente para designar quatro substâncias principais, que são as aflatoxinas $B_{1}, B_{2}, G_{1}$ e $G_{2}$. Estas substâncias, quando submetidas à luz ultravioleta (365 nm), apresentam fluorescência azul-violeta ou esverdeada e, por isso, são representadas pelas letras B ("blue") ou G ("green"). Os índices 1 e 2 referem-se à sua mobilidade em cromatografia de camada delgada (World Health Organization, 1979).

Um fungo aflatoxigênico pode produzir mais de um tipo de aflatoxina. Um isolado de A. flavus, por exemplo, pode produzir as aflatoxinas $B_{1}$ e $B_{2}$, enquanto que $A$. parasiticus pode sintetizar as aflatoxinas $B_{1}, B_{2}, G_{1}$ e $\mathrm{G}_{2}$ (Hesseltine et al. 1970).

Apesar de não se conhecer a função das aflatoxinas dentro dos processos vitais dos organismos que as produzem, elas são extremamente tóxicas ao homem e aos animais, quando presentes na sua alimentação (FAO, 1993). As espécies variam em sua susceptibilidade aos efeitos tóxicos das aflatoxinas, sendo os mesmos influenciados por fatores como estado 
nutricional, saúde, idade e sexo do animal, dentro de cada espécie (Hsieh et al., 1977). Dentre os animais já estudados, o coelho é um animal altamente sensível, enquanto que o camundongo é o mais resistente (Patterson, 1973).

Segundo Smith \& Moss (1985) o conjunto de sintomas resultante da ingestão de uma ou mais doses de alguma micotoxina é denominado micotoxicose. Estas podem ser classificadas em agudas ou crônicas, de acordo com a quantidade de toxinas ingerida ou sensibilidade do animal. A aflatoxicose aguda ocorre quando há ingestão de alimento altamente contaminado, a exemplo do que aconteceu na Índia, onde 74 pessoas morreram, e no Quênia, onde ocorreram 12 óbitos (Park \& Stolof, 1989).

$\mathrm{Na}$ aflatoxicose crônica, alimentos com baixos niveis de aflatoxina são ingeridos por um prolongado período de tempo. O efeito mais comum deste tipo de contaminação é a diminuição da resistência imunológica e o câncer de figado (Shank, 1978; Hsieh, 1986; Mycotoxins, 1989). Esse tipo de intoxicação também está relacionada com cirrose infantil hindu, sindrome de Reye e encefalopatia (Hsieh, 1989).

Os produtos agricolas podem ser contaminados pelos fungos toxigênicos durante o crescimento das plantas, armazenamento e processamento. A quantidade de aflatoxinas está na ordem de $\mu \mathrm{g} / \mathrm{kg}$ até $\mathrm{mg} / \mathrm{kg}$, em alimentos tais como: amendoim, milho, arroz, trigo, sorgo e outros. Em muitos países, são permitidos níveis de aflatoxinas, em produtos 
alimentícios, entre 5 a $50 \mu \mathrm{g} / \mathrm{kg}$ (FAO, 1993). No Brasil, a legislação determinava, até junho de 1996, que os niveis da somatória das aflatoxinas $B_{1}$ e $\mathrm{G}_{1}$ deviam estar abaixo de $30 \mu \mathrm{g} / \mathrm{kg}$ (Brasil, 1977). Em 1996, porém, para adequar às normas do Mercosul, estabeleceu-se um limite máximo de $20 \mu \mathrm{g} / \mathrm{kg}$ para a somatória das aflatoxinas $B_{1}, B_{2}, G_{1}$ e $G_{2}$ nos alimentos (Brasil, 1996).

\subsection{Produção de aflatoxinas}

Hesseltine et al. (1966) mostraram que o grão do amendoim é um substrato apropriado ao crescimento de espécies aflatoxigênicas. Juntamente com a semente de algodão e o milho, o amendoim forma o grupo de produtos agrícolas onde a ocorrência de aflatoxinas é mais freqüente (Jelinek, 1988).

De um modo geral, o crescimento de fungos e a produção de toxinas são afetados por fatores físicos (temperatura, umidade do produto e umidade relativa durante o armazenamento, aeração, luz e danos mecânicos), químicos (fatores nutricionais e presença de fungistáticos) e biológicos (linhagem do microrganismo, crescimento do fungo em competição e destoxificação microbiana realizada pela Flavobacterium aurantiacum). Em surtos no campo, os fatores mais importantes provavelmente seriam temperatura e umidade relativa (Doller, 1969; Jarvis, 1971, Northolt et al., 1976). 
Segundo Diener \& Davis (1966) e Schindler et al. (1967) a temperatura ótima para a produção de aflatoxinas por A. flavus é de 24 a $25^{\circ} \mathrm{C}$. Nestas condições, Diener \& Davis (1966) observaram que, com 5 dias de incubação, a produção de aflatoxinas já era elevada tanto em grãos quanto em meio de cultura. Schroeder \& Hein (1967) afirmaram que a faixa ótima de temperatura para a produção de aflatoxinas está entre 20 e $35^{\circ} \mathrm{C}$.

A temperatura mínima limitante para a produção de aflatoxinas e crescimento do fungo está entre 10 e $13 \pm 1^{\circ} \mathrm{C}$ (Diener \& Davis 1967, 1969b, Schroeder \& Hein 1967). A temperatura máxima, por outro lado, está entre 40 e $41,5 \pm 1,5^{\circ} \mathrm{C}$ (Diener \& Davis 1967, 1969b, Schindler et al. 1967, Schroeder \& Hein 1967).

Para A. parasiticus, a faixa ótima de temperatura para produção de aflatoxinas é de 25 a $30^{\circ} \mathrm{C}$. Nestas condições, a produção de aflatoxinas já é elevada com 3 dias de incubação, tanto em grãos quanto em meio de cultura (Diener \& Davis 1966).

Diener \& Davis $(1967,1969 b)$ verificaram que a umidade relativa do ar limitante para a produção de aflatoxinas por A. flavus é de 83 a $85 \pm 1 \%$, a $30^{\circ} \mathrm{C}$. De acordo com Jarvis (1971), se o teor de umidade do amendoim não for rapidamente baixado para menos de $9 \%$ logo após o arranquio, o crescimento de $A$. flavus e $A$. parasiticus irá ocorrer. 
A infecção do grão de amendoim por A. flavus pode ocorrer através das próprias flores. Esporos deste fungo, ao serem depositados em seu estígma, podem germinar e, assim, contaminar os tecidos dos grãos em desenvolvimento (Smith \& Moss, 1985). Além da contaminação nos vários estágios de produção do amendoim, esta pode ainda ocorrer durante o póscolheita e o armazenamento do grão (Diener et al., 1987).

Através de estudos detalhados, Cole (1989a) redefiniu o papel da contaminação do grão de amendoim por A. flavus na fase de pré-colheita, passando a considerar sua importância maior do que a infecção durante o armazenamento.

As operações de pós-colheita do amendoim no campo em algumas regiões do mundo podem ocorrer em condições de clima quente e úmido. Nesta situação, a secagem do grão é mais lenta e o risco de contaminação por aflatoxinas é alto (Jackson, 1967).

A causa mais comum da contaminação do amendoim por aflatoxinas durante o pós-colheita no campo é a secagem lenta do amendoim e a colheita e ensacamento ainda úmido do mesmo (Fonseca, $\mathrm{H}^{2}$ ).

\footnotetext{
2Fonseca, H. (Escola Superior de Agricultura "Luiz de Queiroz", Departamento de Ciência e Tecnologia Agroindustrial, Piracicaba), comunicação pessoal, 1996.
} 
No armazenamento, a elevada umidade inicial do amendoim é o principal fator a determinar uma alta população fúngica (Diener, 1960). Se a secagem for lenta e o amendoim em casca demorar a atingir um teor de umidade abaixo de $11 \%$, o grau da contaminação por $A$. flavus pode aumentar, elevando assim a contaminação com aflatoxinas. Nesta fase ainda, os grãos podem ser reumedecidos se forem expostos a altas umidades por longos períodos chuvosos, o que também resultará no desenvolvimento de $A$. flavus e, conseqüentemente, na produção de aflatoxinas (Fonseca, $\mathrm{H}^{3}{ }^{3}$ ).

\subsection{Ocorrência de aflatoxinas em amendoim no Brasil}

Antes mesmo da descoberta das aflatoxinas, pesquisadores brasileiros já correlacionavam a intoxicação de animais com a ingestão de subprodutos de amendoim. Em São Paulo, por exemplo, Amaral (1961) relacionou a morte de suínos à ingestão de ração contendo farelo de amendoim, o qual também foi tóxico a cobaias.

Raimo et al. (1962) responsabilizaram a farinha de amendoim pelo progressivo decréscimo na eclodibilidade dos ovos e a baixa produção de carne de frango, em 1958 e 1959, no Estado de São Paulo.

${ }^{3}$ Fonseca, H. (Escola Superior de Agricultura "Luiz de Queiroz", Departamento de Ciência e Tecnologia Agroindustrial, Piracicaba), comunicação Pessoal, 1996. 
Em Minas Gerais, Moraes (1964) analisou 5 amostras de farelo de amendoim obtidos de indústrias de óleo e ração e constatou que as aflatoxinas estavam presentes em todas as amostras analisadas, sendo que algumas delas possuiam níveis de aflatoxina B1 de aproximadamente $7000 \mu \mathrm{g} / \mathrm{kg}$.

Tango et al. (1965/66) verificaram o grau de contaminação por aflatoxinas no amendoim produzido no Estado de São Paulo. Neste estudo foram coletadas, em várias indústrias de óleo, 72 amostras, sendo 37 durante a estação chuvosa (verão) e 35 na estação da seca (inverno). As análises destas amostras mostraram que cerca de $73,0 \%$ e $65,7 \%$, para estação chuvosa e seca, respectivamente, continham aflatoxinas acima de $100 \mu \mathrm{g} / \mathrm{kg}$.

Menezes et al. (1965/66) examinaram 41 amostras de sementes, 33 de torta e 31 de farelo de amendoim de 43 indústrias paulistas de processamento de óleo. Foi constatado que as sementes tinham pelo menos $100 \mu \mathrm{g} / \mathrm{kg}$ de aflatoxinas e que somente $3,2 \%$ dos farelos e $3 \%$ das tortas estavam adequados para a alimentação animal.

Fonseca (1968), determinou os niveis de aflatoxinas $B_{1}$ e $G_{1}$ em 264 amostras de torta e farelo de amendoim que foram coletadas de 40 indústrias de extração de óleo, localizadas nas regiões paulistas: Sorocabana, Noroeste, Paulista Nova e Araraquarense. Todas as amostras analisadas continham aflatoxinas, sendo que $89,8 \%$ das amostras continham níveis acima de $1.000 \mu \mathrm{g} / \mathrm{kg}$ e duas continham niveis de $20.000 \mu \mathrm{g} / \mathrm{kg}$. 
Estudos conduzidos por Fonseca (1973a, 1973b, 1973c, 1975) revelaram a ocorrência de elevados níveis de aflatoxinas em farelo de amendoim nas regiões Noroeste, Paulista Nova, Sorocabana e Araraquarense, do Estado de São Paulo. Das amostras estudadas, menos de 16\% podiam ser consideradas adequadas para alimentação animal. As amostras da estação chuvosa estavam mais contaminadas do que as da estação seca.

Fonseca (1976a, 1976b, 1976c, 1976d) estudou a aflatoxina no amendoim desde sua colheita até a sua industrialização, nas regiões paulistas de Matão, Monte Alto, Santa Adélia e Fernandópolis. As amostragens foram feitas no momento da entrega do amendoim na indústria de óleo, durante o armazenamento e no farelo após a extração do óleo. Cerca de $90 \%$ das amostras estavam contaminadas, sendo que os niveis de aflatoxina aumentaram durante a estocagem. Em geral, estes níveis diminuíram após a extração do óleo.

Fonseca et al. (1982) e Fonseca et al. (1983) efetuaram um levantamento de 2 anos (1981 e 1982) sobre a incidência de aflatoxinas em vários alimentos nas regiões do Vale do Paraiba, Mogiana, Paulista Velha, Araraquarense, Noroeste, Paulista Nova, Sorocabana e Vale do Ribeira-Litoral Sul, no Estado de São Paulo. Nos dois anos de pesquisa, foi observado que a porcentagem média de produtos contaminados com aflatoxina $B_{1}$, acima de 30 
$\mu \mathrm{g} / \mathrm{kg}$, era de aproximadamente $15 \%$ do amendoim cru, $10 \%$ do amendoim torrado salgado, $73 \%$ da pasta de amendoim e $65 \%$ da paçoca.

Em Belo Horizonte, MG, Prado (1983) verificou que 62\% das amostras de amendoim e produtos de amendoim coletadas apresentavam aflatoxinas, sendo que $44 \%$ possuiam mais de $30 \mu \mathrm{g} / \mathrm{kg}$.

Em Campinas, SP, Scussel \& Rodriguez-Amaya (1985) analisaram amostras de amendoim e seus derivados, adquiridos ao acaso em diferentes armazéns. Aproximadamente $50 \%$ das amostras deram resultados positivos para aflatoxina, sendo que destas quase todas apresentaram niveis superiores a $30 \mu \mathrm{g} / \mathrm{kg}$.

Em Ribeirão Preto, SP, Ricciardi \& Ferreira (1986) detectaram aflatoxina $B_{1}$ em $67,2 \%$ das amostras coletadas de amendoim e seus derivados, sendo que $24,5 \%$ apresentaram níveis acima de $30 \mu \mathrm{g} / \mathrm{kg}$.

No Instituto Adolfo Lutz, em São Paulo, SP, Sabino et al. (1989) analisaram amostras de amendoim e seus produtos durante o período de 198087. Embora tenham encontrado contaminações acima do limite permitido pela legislação, a média de incidência e os níveis de aflatoxina variaram de ano para ano, sem padrão definido.

Em Belo Horizonte, MG, estudos realizados por Prado et al. (1989), no período de 1983 a 1988, indicaram que 61,5\% das amostras 
coletadas de amendoim cru estavam contaminadas com aflatoxina $B_{1}$, com níveis variando de 4 a $1032 \mu \mathrm{g} / \mathrm{kg}$.

Fonseca et al. (1991) publicaram os resultados das análises efetuadas em 625 amostras de amendoim descascado, na maioria HPS ("hand picked selected") provenientes do Estado de São Paulo, durante os anos de 1988 e 1989. Em 1988, 52\% das amostras apresentavam-se contaminadas sendo que, 22 amostras continham niveis acima de $500 \mu \mathrm{g} / \mathrm{kg}$. Em 1989, 32\% amostras estavam contaminadas sendo que, 9 amostras continham niveis acima de $500 \mu \mathrm{g} / \mathrm{kg}$. Os níveis médios de aflatoxina foram de $133,8 \mu \mathrm{g} / \mathrm{kg}$ em 1988 e $414,8 \mu \mathrm{g} / \mathrm{kg}$ em 1989.

Sabino et al. (1996) determinaram o teor de aflatoxinas em 321 amostras de amendoim e seus produtos, coletados no estado de São Paulo, pelo Serviço de Inspeção, durante o ano de 1994. Foi observado que, em $36 \%$ das amostras, os níveis das aflatoxinas $B_{1}+G_{1}$ eram superiores a $30 \mu \mathrm{g} / \mathrm{kg}$.

\subsection{Distribuição e separação dos grãos contaminados}

A extrema variabilidade na ocorrência e nos níveis de contaminação com aflatoxinas no amendoim torna a presença destas um problema grave para este produto (Cucullu et al., 1966). 
A contaminação por aflatoxinas em grãos de amendoim não é distribuída de forma homogênea, sendo, muitas vezes, restrita a um número muito pequeno de grãos (Cucullu et al. 1966, Dickens 1977 e Whitaker \& Wiser 1969).

Os grãos pequenos de amendoim são os mais susceptíveis a apresentar maiores niveis de contaminação por aflatoxinas. Blankenship et al. (1973), analisando amostras de amendoim nos Estados Unidos, verificaram que os grãos que passaram pelas peneiras 18/64 e 16/64 $(7,1$ e $6,4 \mathrm{~mm}$, respectivamente), continham médias mais altas de contaminação com aflatoxinas do que os grãos maiores (peneira $20 / 64$ ou $7,9 \mathrm{~mm}$ ). Por esta razão, nos Estados Unidos, os processadores de amendoim aproveitam somente os grãos de tamanho grande (Tiemstra, 1977).

As aflatoxinas estão mais associada aos grãos mais leves de um lote contaminado. Através de uma mesa gravitacional, a maioria dos grãos mais leves podem ser separados dos grãos mais pesados, prática esta muito utilizada nos Estados Unidos (Davidson et al. ${ }^{4}$, citados por Cole, 1989b).

De acordo com Banes (1966), os niveis de aílatoxinas em um lote de amendoim estão correlacionados com a proporção de vagens quebradas,

\footnotetext{
${ }^{4}$ Davidson Jr., J.I.; Holaday, C.E.; Bennett, .C.T. Separation and removal of aflatoxin contaminated kernels in peanut shelling plants: Part I. A case study. Proc. Am. Peanut Res. Educ. Soc., 13: 29-45. 1981.
} 
número de grãos enrugados, rancificados e descoloridos presentes no lote. Quando este material de baixa qualidade é separado e descartado, os grãos de alta qualidade restantes são praticamente livres de aflatoxinas.

Bockelée-Morvan \& Gillier (1974) verificaram que as vagens de amendoim perfuradas apresentavam maior contaminação por aflatoxinas do que as vagens intactas. A separação das vagens danificadas resultou na diminuição do teor de aflatoxina dos lotes.

Em outro experimento relatado pelos mesmos pesquisadores, 4 amostras de grãos de amendoim, provenientes do Senegal, foram classificadas manualmente. Os grãos perfeitos, presentes nas amostras, foram separados e os grãos, com algum defeito, foram classificados em: a) grãos imaturos, b) grãos com ataque visível de fungo, c) grãos quebrados e despeliculados e d) grãos com coloração anormal sem ataque fúngico visivel. Os grãos das classes b e d apresentavam, na média dos lotes, 88,2 e $8,2 \%$, respectivamente, da contaminação por aflatoxinas encontrada no total dos grãos com defeito e representavam 12,0 e 9,1\%, respectivamente, em peso, do total dos grãos com algum defeito.

Cole (1989b) estudou a distribuição de aflatoxinas entre os tipos de grãos de amendoim em amostras retiradas de lotes contaminados antes da colheita. Os grãos danificados, debulhados e imaturos apresentaram os maiores niveis de aflatoxina. 
A falta de técnicas de controle da contaminação com aflatoxinas em amendoim antes da colheita aumenta a importância das técnicas de controle nas fases após a colheita (Gnanasekharan \& Chinnan, 1992).

De acordo com Schmidt \& Esser (1985), o controle das aflatoxinas compreende a segregação de lotes contaminados, a descontaminação parcial e a prevenção de futuras contaminações através de métodos de armazenamento adequados.

Os métodos de separação de grãos de amendoim com a finalidade de comercialização já existiam antes mesmo da descoberta das aflatoxinas. Nos Estados Unidos, alimentos embolorados eram considerados produtos ilegais no comércio interestadual desde 1906 (Banes, 1966). Até mesmo os classificadores automáticos já eram desenvolvidos e utilizados, pois o amendoim era comercializado despeliculado e salgado e, por este motivo, grãos danificados ou descoloridos eram retirados, para melhorar seu aspecto visual (Kensler \& Natoli, 1969). Contudo, a partir da descoberta destas substâncias tóxicas, a separaçẩo dos grãos começou a ser utilizada mais intensamente (Goldblatt \& Dollear, 1977).

Hardon \& Kok $(1964)^{5}$, citados por Kensler \& Natoli (1969), retiraram manualmente os grãos com defeitos de um lote de amendoim e

\footnotetext{
${ }^{5}$ Hardon, H.J. \& Kok, H.A. Aflatoxin in peanuts. Conserva, 12(9), 211-216.
} 1964. 
obtiveram um material contendo $3.200 \mu \mathrm{g} / \mathrm{kg}$ de aflatoxinas; os grãos restantes não apresentavam niveis detectáveis de aflatoxinas.

Conforme Chiou et al. (1994), a torração dos grãos a $160^{\circ} \mathrm{C}$ por 15 minutos seguida de despeliculamento poderia melhorar a eficiência da classificação manual. Isto porque o crescimento do fungo no amendoim nem sempre resulta em descoloração significativa e, por esse motivo, mesmo grãos perfeitos podem conter aflatoxinas. Durante a torração, a coloração de grãos infectados por fungos muda mais rapidamente do que a dos grãos sadios. Quando a classificação foi feita em grãos torrados e despeliculados, o material restante não possuía aflatoxina a níveis detectáveis.

A classificação eletrônica é muito eficiente em remover grãos contaminados com aflatoxinas, como foi demonstrado por Kensler \& Natoli (1969) em um experimento com dois lotes de amendoim. No primeiro lote, o nivel inicial de aflatoxinas caiu de $25 \mathrm{ppb}$ para menos de $5 \mathrm{ppb}$, enquanto que no segundo lote, a quantidade de aflatoxinas passou de 20 para $5 \mu \mathrm{g} / \mathrm{kg}$. Em ambos os casos, o material rejeitado continha 350 e $100 \mu \mathrm{g} / \mathrm{kg}$, respectivamente. Geralmente, a classificação eletrônica é precedida pela torração e despeliculamento, podendo ser feita com grãos inteiros ou partidos.

Cole (1989b) verificou que a classificação eletrônica de grãos de amendoim, na maioria dos lotes, reduziu eficientemente os niveis de aflatoxina, que originalmente estavam acima de $30 \mu \mathrm{g} / \mathrm{kg}$. Entretanto, a existência de 
lotes em que a primeira passagem pela máquina classificadora não causou redução nos níveis para menos de $30 \mu \mathrm{g} / \mathrm{kg}$ mostra que há necessidade de se observar cuidadosamente os fatores envolvidos na eficiência deste tipo de classificação, a fim de que esta produza os efeitos desejados.

De acordo com Pelletier \& Reizner (1992), a classificação manual do amendoim é mais eficiente na remoção de grãos contaminados por aflatoxinas do que a eletrônica.

A eficiência da classificação eletrônica pela cor seguida pela catação manual, para remoção dos grãos contaminados em lotes de amendoim destinados à comercialização, foi estudada por Dickens \& Whitaker (1975). Este procedimento resultou na eliminação de, em média, $72 \%$ das aflatoxinas das amostras contaminadas; entretanto, foi observada uma grande variação na eficiência da remoção das aflatoxinas pela classificação eletrônica entre os lotes. De acordo com Cole (1989b), a associação destes dois métodos é mais indicada nos anos de maior probabilidade de ocorrência de aflatoxinas ainda no campo.

A classificação manual tem aplicações limitadas, mas importantes; embora seu custo seja elevado, mesmo com a disponibilidade dos equipamentos eletrônicos, ainda é desejável uma classificação manual final, para assegurar a qualidade do produto a ser comercializado (Kensier \& Natoli, 1969). 
Alguns pesquisadores testaram outras técnicas de separação dos grãos de lotes contaminados, baseadas nas suas caracteristicas físicas (Pettit \& Geiger 1981; Kirksey et al. 1987, 1989; Henderson et al. 1991; Gnanasekharan \& Chinnan 1992; Pelletier \& Reizner 1992).

Kirksey et al. (1987) avaliaram a separação por densidade através da flutuação em água dos grãos contaminados de amostras de amendoim. Mesmo conseguindo uma redução de $80-90 \%$ do conteúdo das aflatoxinas nas amostras, os pesquisadores observaram que as metades de grãos, os grãos pequenos (<16/64 polegadas) e os grãos sem película não seguiam o mesmo padrão de separação dos demais grãos.

Kirksey et al. (1989) analisaram a relação entre a propensão para flutuar e o conteúdo de aflatoxinas em grãos de amendoim. Foi observada uma associação positiva entre o nivel de aflatoxinas, o tamanho do lume do grão (espaço vazio entre os cotilédones) e a sua propensão para flutuar. Segundo estes pesquisadores, o ar presente no lume daria condições para a flutuação, o crescimento de fungo e a produção de aflatoxinas. Em seu experimento, os grãos que flutuavam continham em média $95 \%$ da contaminação por aflatoxinas existente nas amostras.

Henderson et al. (1991) desenvolveram e patentearam, nos Estados Unidos da América, uma técnica de separação dos grãos por diferença 
de densidade, na qual ocorria a flutuação dos grãos contaminados em um liquido de peso específico entre 0,9 e 1,2.

Segundo Gnanasekharan \& Chinnan (1992), a separação por diferença de densidade consegue remover grãos altamente contaminados que possam estar entre os grãos maduros e visivelmente sadios. Estes grãos, normalmente, não são separados pela classificação eletrônica.

Pelletier \& Reizner (1992) avaliaram o método de seleção de grãos de amendoim através da fluorescência, o qual não se mostrou eficiente na remoção dos grãos contaminados com aflatoxina. 


\section{MATERIAL E MÉTODOS}

\subsection{Material}

O material utilizado foi amendoim em casca, da variedade Tatu, que é a mais cultivada no Estado de São Paulo, proveniente de lotes sabidamente contaminados com aflatoxinas. As amostras foram retiradas no período de maio a junho de 1994 de uma indústria de óleo, localizada na cidade de Junqueirópolis, no Estado de São Paulo.

\subsection{Métodos}

\subsubsection{Método de amostragem}

O experimento foi realizado com 15 lotes, constituídos por 2 sacos cada um (cada saco de amendoim continha $25 \mathrm{~kg}$ de amendoim em casca). Estes lotes foram devidamente numerados, sendo retirada uma amostra de 
cada um para verificar se havia contaminação com aflatoxinas. Apenas 10 lotes apresentaram-se contaminados com a toxina. A contaminação média por aflatoxinas apresentada por estes lotes foi de $1.968,28 \mu \mathrm{g} / \mathrm{kg}$. Estes foram, então, descascados mecanicamente na própria fábrica e, de cada lote, foram retiradas amostras compostas de, aproximadamente, $20 \mathrm{~kg}$ de grãos de amendoim. Obteve-se um total de 10 amostras, as quais foram classificadas de acordo com as normas do Ministério da Agricultura para obtenção dos 9 tipos de grãos de amendoim.

\subsubsection{Determinação do teor da umidade inicial}

Para a determinação da umidade inicial do amendoim coletado, foram retiradas, de cada uma das amostras, 2 sub-amostras de $50 \mathrm{~g}$ de amendoim sem casca, as quais foram colocadas em estufa a $105 \pm 3^{\circ} \mathrm{C}$ por 24 horas, de acordo com Brasil (1976).

\subsubsection{Método de classificaçãa dos grãos}

As amostras de cada lote recebidas no laboratório foram classificadas de acordo com as normas do Ministério da Agricultura do Brasil, Portaria número 329 (Brasil, 1981). 
Após a classificação, os seguintes tipos de grãos foram obtidos:

a) grãos mofados - grãos ou fragmentos contaminados por fungos (bolores), apresentando a olho nu aspecto aveludado.

b) grãos ardidos - grãos ou pedaços de grãos que apresentavam alterações em sua coloração normal, causada pela ação excessiva do calor e umidade ou fermentação. Incluiram-se nesta classe os grãos rancificados, os quais apresentavam cor anormal e odor desagradável.

c) grãos danificados - grãos que apresentavam danos causados por agentes biológicos (insetos em qualquer de suas fases de desenvolvimento, roedores e ácaros), assim como danificados por diferentes causas (danos mecânicos e outros).

d) grãos brotados - grãos que se apresentavam visivelmente germinados, caracterizando inclusive o rompimento da pelicula.

e) grãos chochos - grãos que se apresentavam enrugados, praticamente desprovidos de massa interna e enrijecidos.

f) grãos imaturos - grãos que não atingiram o seu desenvolvimento fisiológico completo (maturação), apresentando-se geralmente descoloridos e menores que o grão maduro normal.

g) grãos partidos ou quebrados - cotilédone (banda) ou fragmentos de grãos, qualquer que seja o seu tamanho. 
h) grãos despeliculados - grãos que se apresentavam desprovidos de sua película (testa).

i) grãos peliculados - grãos que se apresentam providos de sua película.

Após a separação dos grãos de amendoim de cada amostra, a quantidade de cada tipo foi pesada e acondicionada em sacos de papel tipo "kraft" e identificados.

\subsubsection{Método de análise de aflatoxinas}

Após a classificação dos grãos, cada tipo foi analisado para verificar a presença de aflatoxinas.

\subsubsection{Preparo da amostra}

Cada tipo de grão foi triturado de modo a obter-se um material com granulometria equivalente a uma peneira de malha 20 "mesh". O método para a trituração e homogeneização dos grãos levou em consideração a quantidade obtida na seleção dos mesmos.

Nos tipos de grãos cuja amostra tinha peso superior a $300 \mathrm{~g}$, empregou-se a metodologia de Velasco \& Morris (1976), modificada, para a 
obtenção de uma pasta ("slurry"). A proporção amendoim : água destilada foi de 1:1,5 e a trituração foi realizada em liqüidificador industrial por 3 minutos.

Quando a quantidade de amendoim em cada tipo foi maior que $1 \mathrm{~kg}$, foram feitos "slurries" de $1 \mathrm{~kg}$, tantos quantos foram necessários e, de cada um, retirou-se uma parcela de $100 \mathrm{~g}$, que foram reunidas em liqüidificador para homogeneização e retirada das amostras analíticas, segundo a FAO (1993).

Seguindo recomendação de Scott (1990), item 977.16, foram triturados a seco, em multiprocessador, os grãos de amostras cujo peso era igual ou inferior a $300 \mathrm{~g}$, a fim de obter um material com granulometria equivalente a uma peneira de malha 20 "mesh".

As análises de cada tipo de grão foram realizadas em duplicata, com exceção dos tipos de grãos com quantidades menores do que $50 \mathrm{~g}$.

\subsubsection{Extração das aflatoxinas}

A extração das aflatoxinas, a partir da amostra analítica, seguiu a metodologia de Pons Jr. et al. (1966), com algumas modificaçōes.

Das amostras preparadas com "slurry", foram retiradas amostras analíticas de $100 \mathrm{~g}$, as quais foram colocadas em erlenmeyer de $500 \mathrm{ml} \mathrm{e}$ extraídas com $200 \mathrm{ml}$ de acetona e $5 \mathrm{~g}$ de celite em agitador mecânico por 30 minutos; a seguir, foram filtradas em papel de filtro qualitativo. Do filtrado 
obtido, tomou-se uma alíquota de $120 \mathrm{ml}$ em um béquer de $400 \mathrm{ml}$ ao qual adicionaram-se $100 \mathrm{ml}$ de água destilada, $25 \mathrm{ml}$ de solução de acetato de chumbo a $20 \%$ e $5 \mathrm{~g}$ de celite. Em seguida, a mistura foi agitada em movimentos circulares, deixada em repouso por 5 minutos e filtrada. Do filtrado, foram retirados $170 \mathrm{ml}$, os quais foram transferidos para um funil de separação de $250 \mathrm{ml}$.

Para a extração das aflatoxinas do filtrado, foram utilizadas duas porções de $25 \mathrm{ml}$ de clorofórmio. Após a adição de cada porção, agitou-se fortemente durante 1 minuto, aguardando-se a separação das fases. As fases clorofórmicas (inferiores) foram recolhidas, reunidas e passadas para um balão de destilação, através de um funil, com uma camada de $5 \mathrm{~g}$ de sulfato de sódio anidro. Após a segunda fase clorofórmica ter sido recolhida, o suif́ato de sódio anidro foi lavado com $25 \mathrm{ml}$ de clorofórmio.

O extrato contido no balão de destilação foi concentrado em evaporador a vácuo e então transferido para frasco âmbar de $5 \mathrm{ml}$, através de lavagens com clorofórmio até completar o volume de $5 \mathrm{ml}$. Em seguida, o frasco âmbar foi levado até a secura em banho-maria sob fluxo de nitrogênio e o extrato redissolvido em $1 \mathrm{ml}$ de benzeno.

Das amostras preparadas em multiprocessador, foram retiradas amostras analíticas de 50g, as quais sofreram extração com $250 \mathrm{ml}$ de acetona aquosa $(85+15)$, em agitador mecânico por 30 minutos. O extrato foi filtrado 
em papel de filtro qualitativo e tomou-se uma alíquota de $100 \mathrm{ml}$, em um béquer de $250 \mathrm{ml}$, no qual foram adicionados $80 \mathrm{ml}$ de água destilada, $20 \mathrm{ml}$ de solução de acetado de chumbo a $20 \%$ e $5 \mathrm{~g}$ de celite. Em seguida, a mistura foi agitada em movimentos circulares, deixada em repouso por 5 minutos e filtrada. Do filtrado, retiraram-se $100 \mathrm{ml}$, os quais foram transferidos para um funil de separação de $250 \mathrm{ml}$. A partir deste ponto, procedeu-se como na extração das amostras preparadas através de "slurry".

Quando a quantidade de grãos da amostra foi inferior a $50 \mathrm{~g}$, a extração foi realizada com $25 \mathrm{~g}$ da amostra e a quantidade de solventes adicionados foi proporcionalmente reduzida.

\subsubsection{Detecção e quantificação das aflatoxinas}

A deteç̧ão das aflatoxinas foi realizada por cromatografia de camada delgada (CCD), utilizando-se cromatofolhas de silica-gel 60G, sendo a quantificação feita por comparação visual com padrões. Utilizou-se desenvolvimento unidirecional e, nas amostras que apresentaram extratos com muitos interferentes (amostras de grãos mofados, ardidos, imaturos, chochos e danificados), empregou-se o desenvolvimento bidirecional nas placas de quantificação. 
A cromatografia unidirecional foi utilizada tanto para placas qualitativas como para as placas quantitativas. Para verificar a presença da toxina, bem como a intensidade da fluorescência, foram aplicados $1 \mu \mathrm{l}$ das amostras e $5 \mu$ do padrão nas placas, as quais foram desenvolvidas primeiramente no sistema de solventes hexano + acetato de etila $(1+1)$, para limpeza dos interferentes. Em seguida, foram retiradas da cuba de desenvolvimento, deixadas secar em capela e colocadas para desenvolver, no mesmo sentido, no sistema de solventes tolueno + acetato de etila + ácido fórmico $86 \%(5+4+1)$.

O esquema da placa bidirecional está representado na Figura 1. Na posição $A$ foi aplicada a alíquota $(x \mu l)$ da amostra; na posição $B, 3 \mu l$ do padrão de aflatoxinas e, nas posições $C, D$ e $E$ foram aplicados 3 , 4 e $6 \mu \mathrm{l}$ respectivamente, dos padrões das aflatoxinas. As placas foram desenvolvidas primeiramente na direção 1 (Figura 1), empregando-se o sistema de solventes clorofórmio + acetona $(9+1)$, depois retiradas da cuba, deixadas secar e colocadas para desenvolver na $2^{\mathrm{a}}$ direção no sistema de solventes tolueno + acetato de etila + ácido fórmico $86 \%(5+4+1)$.

Quando necessário, foram feitos ajustes na concentração dos extratos da amostra através da concentração ou diluição, para melhor quantificação. 


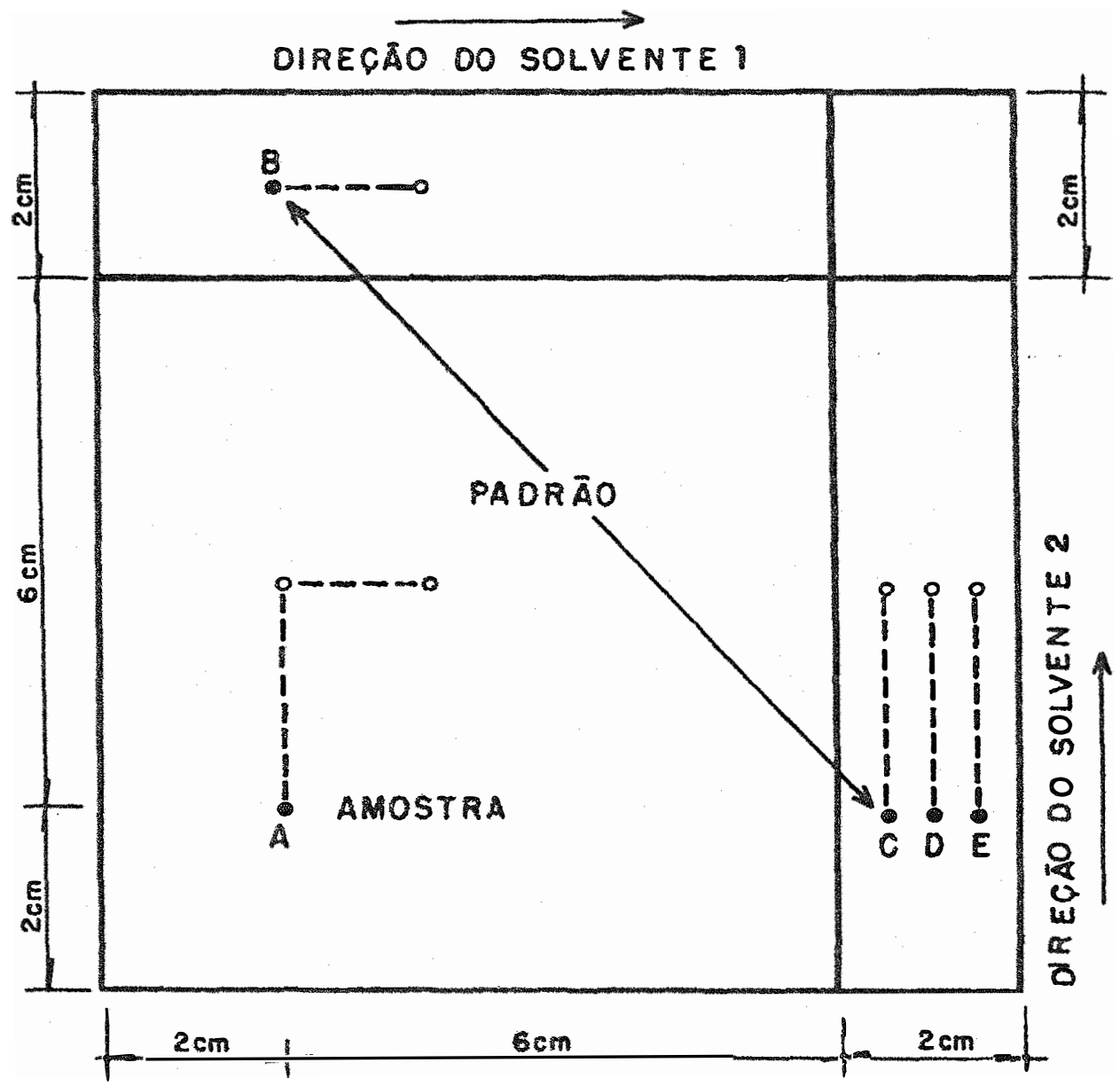

Figura 1. Esquema da divisão da placa de cromatografia bidirecional e disposição das alíquotas do padrão e extrato da amostra. 
Após a correta comparação, o cálculo da concentração das aflatoxinas foi efetuado aplicando-se a seguinte fórmula:

$$
\frac{\mathrm{Y} \cdot \mathrm{S} \cdot \mathrm{V}}{\mathrm{X} \cdot \mathrm{W}}=\mu \mathrm{g} / \mathrm{kg} \text { de toxina ou } \mathrm{ppb}
$$

onde,

$$
\begin{aligned}
\mathrm{Y}= & \text { concentração do padrão em } \mu \mathrm{g} / \mathrm{ml} ; \\
\mathrm{S}= & \text { microlitros do padrão da toxina com fluorescência } \\
& \text { equivalente à da amostra; } \\
\mathrm{V}= & \text { microlitros do volume final do extrato da amostra; } \\
\mathrm{X}= & \text { microlitros aplicados do extrato final; } \\
\mathrm{W} & =\text { peso da amostra, em gramas, no extrato final. }
\end{aligned}
$$

O limite de detecção das aflatoxinas na placa unidirecional foi de $1 \mu \mathrm{g} / \mathrm{kg}$ e na placa bidirecional foi de $0,5 \mu \mathrm{g} / \mathrm{kg}$.

\subsubsection{Confirmação}

A confirmação das aflatoxinas foi efetuada por derivação quimica, utilizando-se para isso o ácido trifluoroacético, segundo a metodologia de Scott (1990), item 985.17. 


\section{RESULTADOS E DISCUSSÃO}

\subsection{Teor de Umidade}

O teor médio de umidade nas amostras de amendoim utilizadas no experimento estava abaixo de $8 \%$ (Figura 2). Deste modo, acredita-se que a contaminação com aflatoxinas não tenha se alterado durante o experimento, uma vez que, de acordo com Cole (1989a), este teor de umidade é considerado seguro para armazenamento de grãos de amendoim.

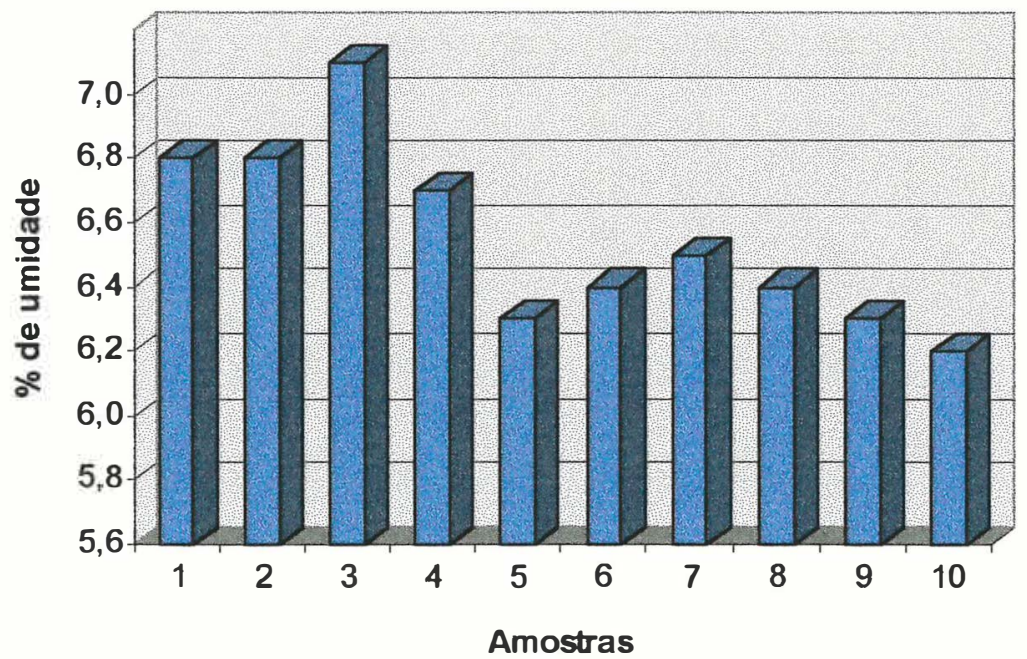

Figura 2. Teor médio (em percentagem) da umidade das amostras de amendoim. 


\subsection{Distribuição da contaminação das aflatoxinas nos diversos tipos de} grãos

Os resultados referentes à análise de aflatoxinas realizados em duplicata nos 10 lotes estão na Tabela 1.

O lote número 10 foi descartado porque apresentou elevada infestação por insetos, fazendo com que aproximadamente $55 \%$ do lote, em peso, correspondesse a grãos danificados e apenas $15,6 \%$ do peso do lote fosse de grãos peliculados, estando este valor muito abaixo dos padrões do Ministério para comercialização do amendoim. Além disso, a contaminação com aflatoxinas foi extremamente elevada nos vários tipos de grãos deste lote, tendo apresentado, no peliculado, $1627 \mu \mathrm{g} / \mathrm{kg}$, que é 11 vezes superior à média dos demais lotes (Tabela 1).

As amostras de amendoim eram provenientes de lotes destinados à extração de óleo e, portanto, já era esperado encontrar altos níveis de contaminação por aflatoxinas (Figura 3). 
Tabela 1. Teor das aflatoxinas $B_{1}+B_{2}+G_{1}+G_{2}$, em $\mu g / k g$, nos tipos de grãos analisados em duplicata, de cada lote.

\begin{tabular}{|c|c|c|c|c|c|c|c|c|c|}
\hline Amostra & Mofado & Brotado & Ardido & Imaturo & Chocho & Dani ficado & Peli cul ado & Quebr ado & Despeli cul ado \\
\hline $1 \mathrm{a}$ & 1.154 & 240 & 38 & 56 & 7 & 16 & N.D. & N.D. & 5 \\
\hline $1 \mathrm{~b}$ & 1.154 & 271 & 38 & 56 & 7 & 16 & N.D. & N.D. & 5 \\
\hline $2 a$ & 12.097 & 10.138 & 8.434 & 1.998 & 2.317 & 1.525 & 71 & 20 & 220 \\
\hline $2 b$ & 12.097 & 11.542 & 8.434 & 1.717 & 2.3332 & 1.172 & 68 & 25 & 200 \\
\hline $3 a$ & 15.899 & 3.507 & 1.401 & 11.013 & 622 & 207 & 148 & 32 & 58 \\
\hline $3 b$ & 18.707 & 2.856 & 1.401 & 10.159 & 622 & 207 & 148 & 32 & 58 \\
\hline $4 a$ & 14.705 & 3.824 & 1.836 & 265 & 384 & 34 & 48 & N.D. & N.D. \\
\hline $4 \mathrm{~b}$ & 14.705 & 4.290 & 2.187 & 321 & 384 & $\$ 8$ & 23 & N.D. & N.D. \\
\hline $5 a$ & 6.751 & 2.047 & 2.787 & 573 & 2.230 & 297 & 44 & 22 & 166 \\
\hline $5 b$ & 6.751 & 2.047 & 2.787 & 573 & 2230 & 297 & 44 & 23 & 166 \\
\hline $6 a$ & 23.943 & 10.011 & 11.696 & 9.375 & 1.737 & 2.454 & 510 & 463 & N.D. \\
\hline $6 \mathrm{~b}$ & 19.425 & 11.971 & 11.783 & 9.375 & 1.737 & 2.547 & 510 & 463 & N.D. \\
\hline $7 a$ & 3.641 & 3.639 & 991 & 1.505 & 423 & 461 & 112 & 21 & 20 \\
\hline $7 b$ & 4.146 & 3.841 & 821 & 1624 & 423 & 461 & 143 & 21 & 34 \\
\hline $8 a$ & 22.146 & 13.752 & 2.752 & 3.974 & 224 & 648 & 181 & N.D. & 27 \\
\hline $8 b$ & 22.146 & 13.752 & 2752 & 3974 & 224 & 648 & 181 & N.D. & 22 \\
\hline $9 a$ & 25.198 & 14.612 & 7.241 & 4.205 & 5.792 & 1.325 & 206 & 199 & 29 \\
\hline $9 \mathrm{~b}$ & 25.907 & 14.482 & 5.131 & 4202 & $\star$ & 1.325 & 206 & 190 & 29 \\
\hline $10 a$ & 15.042 & 22.000 & 23.750 & 15862 & 12.901 & 11.343 & 1.627 & 66 & N.D. \\
\hline $10 b$ & 19.448 & 20.611 & 23854 & 15.862 & $\star$ & 11.343 & 1.627 & 66 & * \\
\hline
\end{tabular}

* Não havia grãos suficientes para fazer análise em duplicata.

N.D. $=$ não detectada

$a$ e $b=$ repetições

Lote 10 = descartado por ter apresentado elevada infestação por inseto. 


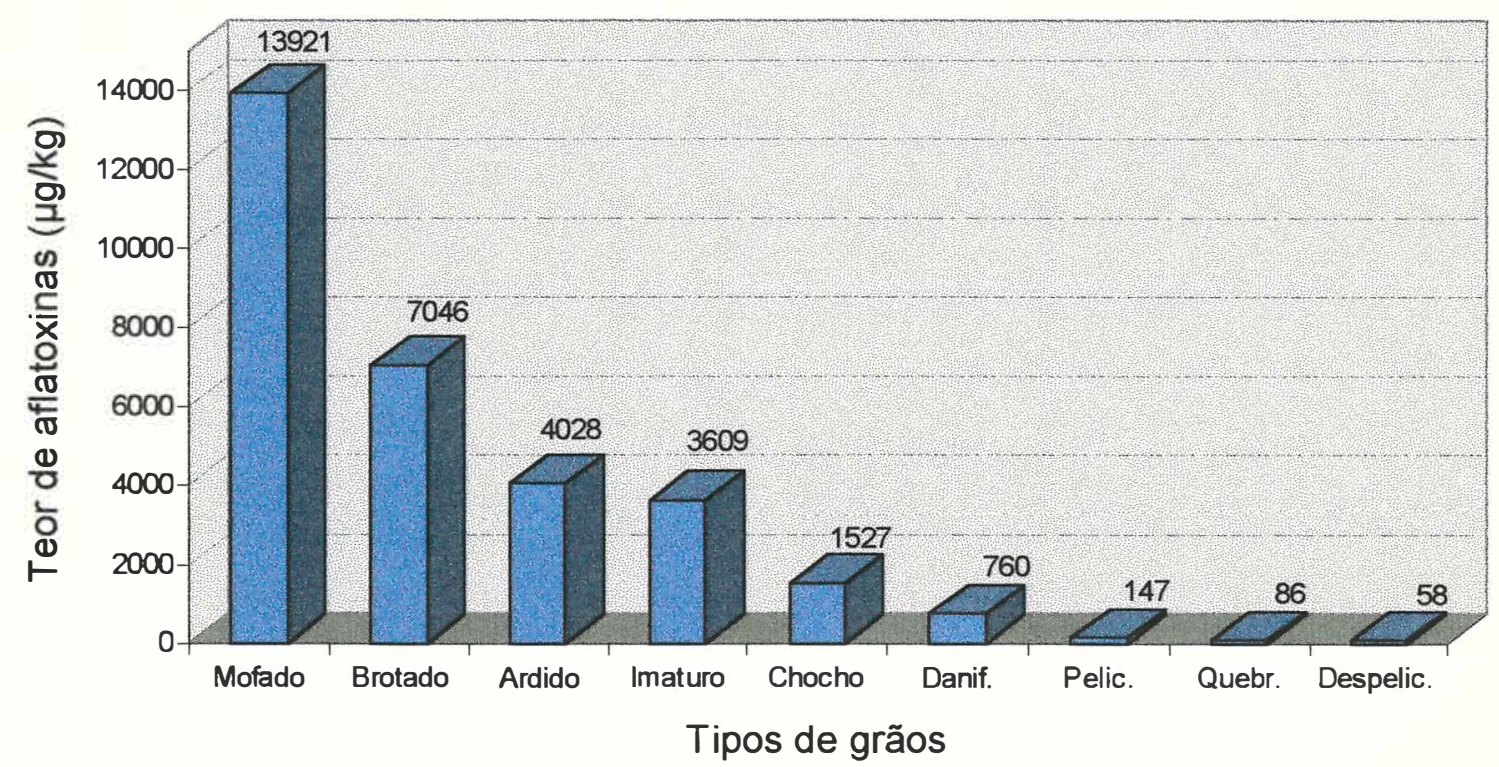

Figura 3. Valores médios de aflatoxinas $\left(B_{1}+B_{2}+G_{1}+G_{2}\right)$ nos diferentes tipos de grãos de amendoim.

Dentro de cada tipo de grão, foi observada uma grande variação do teor de aflatoxinas entre os lotes (Tabelas 2 e 3), conseqüência da extrema heterogeneidade da distribuição da contaminação com aflatoxinas. Esta característica também foi observada por outros pesquisadores, como Cucullu et al. (1966), Whitaker \& Wiser (1969) e Dickens (1977) e é considerada um dos maiores entraves na amostragem de amendoim.

Os grãos peliculados, despeliculados e quebrados foram os tipos que se apresentaram menos contaminados. Mesmo assim, apenas uma amostra de grãos peliculados, 3 de quebrados e 3 de despeliculados possuíam nível de aflatoxinas abaixo de $20 \mu \mathrm{g} / \mathrm{kg}$, limite máximo estabelecido pela legislação brasileira (Tabela 2). 


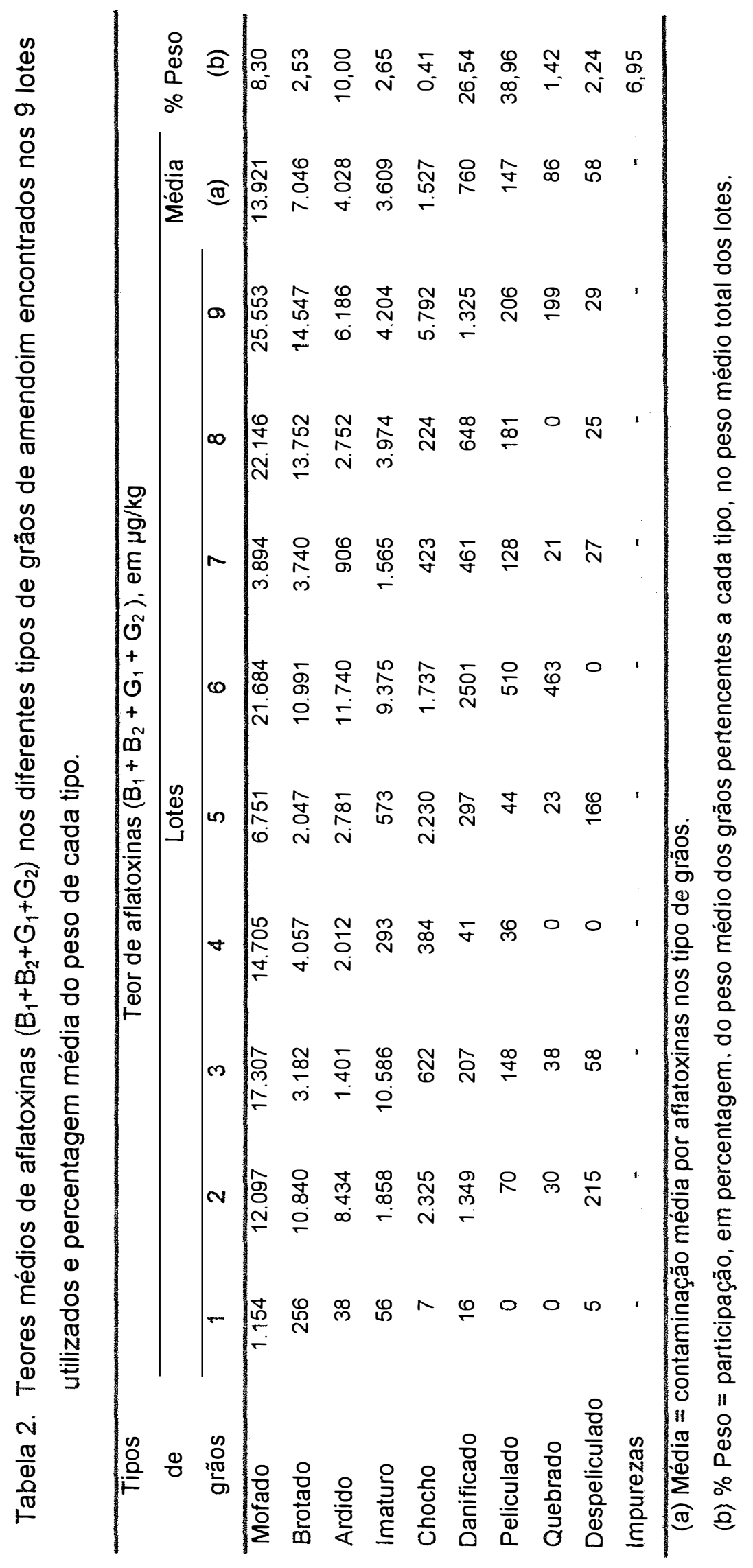


Tabela 3. Variação da contaminação com aflatoxinas nos vários tipos de grãos.

\begin{tabular}{lccc}
\hline \multicolumn{1}{c}{ Tipos } & $\begin{array}{c}\text { Teor médio de } \\
\text { Aflatoxinas }(\mu \mathrm{g} / \mathrm{kg})\end{array}$ & $\begin{array}{c}\text { Desvio padrão } \\
\text { da média }\end{array}$ & $\begin{array}{c}\text { Coeficiente de } \\
\text { variação (\%) }\end{array}$ \\
\hline Mofado & 13.921 & $2.871,24$ & 61,87 \\
Brotado & 7.046 & $1.814,61$ & 77,30 \\
Ardido & 4.028 & $1.308,95$ & 97,49 \\
Imaturo & 3.609 & $1.304,34$ & 108,41 \\
Chocho & 1.527 & 609,16 & 119,67 \\
Danificado & 760 & 273,60 & 107,92 \\
Peliculado & 147 & 51,00 & 104,07 \\
Quebrado & 86 & 51,50 & 179,54 \\
Despeliculado & 58 & 26,02 & 133,81 \\
\hline
\end{tabular}

O tipo mofado foi o que registrou a maior contaminação com aflatoxinas, apresentando uma média de $13.921 \mu \mathrm{g} / \mathrm{kg}$, participando, deste modo, com 55,04\% da contaminação dos lotes (Tabela 4). Esta contaminação foi, aproximadamente, 94, 165 e 240 vezes maior do que aquela registrada para os grãos peliculados, quebrados e despeliculados, respectivamente.

Além do mofado, também apresentaram níveis muito altos os tipos brotados, ardidos, imaturos, chochos e danificados, nos quais foram encontrados, respectivamente, 7.046, 4.028, 3.609, 1.527 e 760 Mg/kg (Tabela 4). 
Tabela 4. Teores médios de aflatoxinas $\left(B_{1}+B_{2}+G_{1}+G_{2}\right)$, média da participação na contaminação dos 9 lotes e percentagem média do peso nos diferentes tipos de grãos de amendoim.

\begin{tabular}{|c|c|c|c|c|c|}
\hline $\begin{array}{c}\text { Tipo } \\
\text { de grãos }\end{array}$ & $\begin{array}{c}\text { Peso } \\
\text { médio }(\mathrm{g})\end{array}$ & $\begin{array}{l}\% \text { média } \\
\text { do peso }\end{array}$ & $\begin{array}{l}\text { Teor médio de } \\
\text { aflatoxinas } \\
(\mu \mathrm{g} / \mathrm{kg})\end{array}$ & $\begin{array}{l}\text { Quantidade total de } \\
\text { aflatoxina ( } \mu \mathrm{g}) \text { em } \\
\text { cada tipo de grão }\end{array}$ & $\begin{array}{c}\text { Parlicipação da } \\
\text { contaminação } \\
\text { no lote (\%) }\end{array}$ \\
\hline Mofado & $1.630,31$ & 8,30 & 13.921 & $22.695,48$ & 55,04 \\
\hline Brotado & 496,81 & 2,53 & 7.046 & $3.500,49$ & 8,49 \\
\hline Ardido & $1.962,92$ & 10,00 & 4.028 & $7.906,62$ & 19,17 \\
\hline Imaturo & 519,47 & 2,65 & 3.609 & $1.874,76$ & 4,55 \\
\hline Chocho & 80,96 & 0,41 & 1.527 & 123,63 & 0,30 \\
\hline Danificado & $5.211,57$ & 26,54 & 760 & $3.960,80$ & 9,61 \\
\hline Peliculado & $7.651,02$ & 38,96 & 147 & $1.124,70$ & 2,73 \\
\hline Quebrado & 278,49 & 1,42 & 84 & 23,39 & 0,06 \\
\hline Despeliculado & 439,91 & 2,24 & 58 & 25,51 & 0,06 \\
\hline Impurezas & $1.365,00$ & 6,95 & - & - & - \\
\hline Total & $19.636,45$ & 100,00 & 31.180 & $41.235,39$ & 100,00 \\
\hline
\end{tabular}

Resultados semelhantes foram obtidos por Bockelée-Morvan \& Gillier (1974), em trabalho realizado no Senegal. Os grãos mofados foram os que apresentaram maiores niveis de contaminação por aflatoxinas, seguidos por grãos com coloração anormal e sem ataque visivel de fungo, grãos esses que correspondem à categoria dos grãos ardidos na classificação utilizada neste estudo. Com exceção dos grãos peliculados, os que apresentaram 
menores teores foram os grãos quebrados e despeliculados, a exemplo do encontrado no presente trabalho.

De acordo com Bockelée-Morvan \& Gillier (1974), a seleção de grãos de amendoim, dentro de um lote, possibilita uma considerável melhoria na sua qualidade, com relação à contaminação por aflatoxinas. Em sua pesquisa, retirando-se os grãos mofados, imaturos e de coloração anormal, que corresponderam a $18 \%$, em peso, do lote, este ficaria praticamente livre de aflatoxinas.

Cole (1989b) também eliminou as categorias de grãos mais contaminados de um lote, as quais correspondiam a $8 \%$ em peso, conseguindo reduzir em $99,7 \%$ as aflatoxinas totais do mesmo.

Conforme já observado por Bockelée-Morvan \& Gillier (1974), a segregação dos tipos de grãos mais contaminados em lotes com altos niveis de aflatoxinas não é vantajosa, uma vez que o lote final continuará contendo níveis de toxinas acima do permitido pela legislação. No presente estudo, onde os grãos peliculados e despeliculados estavam com altos niveis de aflatoxinas, a eliminação dos quatro tipos de grãos que mais contribuíram para a contaminação do lote (mofados, brotados, ardidos e danificados) resultaria na redução da contaminação por aflatoxinas de $2.100 \mu \mathrm{g} / \mathrm{kg}$ para $161 \mu \mathrm{g} / \mathrm{kg}$. Embora a descontaminação tenha sido apreciável, o produto ainda estaria impróprio para consumo humano. 
Em contrapartida, em lotes de melhor qualidade, a segregação dos grãos contaminados poderá fornecer melhores resultados. No lote 1, por exemplo (Tabela 5), a eliminação dos grãos mofados e brotados, os quais correspondem a $6,5 \%$ do peso do lote, reduziria a contaminação do lote de $65 \mu \mathrm{g} / \mathrm{kg}$ para $9,3 \mu \mathrm{g} / \mathrm{kg}$. Como este valor está dentro dos limites permitidos pelas legislações brasileira e do Mercosul, este lote tornar-se-ia adequado para o consumo.

Tabela 5. Teores médios de aflatoxinas $\left(B_{1}+B_{2}+G_{1}+G_{2}\right)$ nos diferentes tipos de grãos de amendoim encontrados no lote 1 , sua participação na contaminação e percentagem média do peso de cada tipo.

\begin{tabular}{lccccc}
\hline \multicolumn{1}{c}{$\begin{array}{c}\text { Tipo de } \\
\text { grãos }\end{array}$} & $\begin{array}{c}\text { Peso } \\
(\mathrm{g})\end{array}$ & $\begin{array}{c}\text { \% em } \\
\text { peso }\end{array}$ & $\begin{array}{c}\text { Teor de } \\
\text { aflatoxina } \\
(\mu \mathrm{g} / \mathrm{kg})\end{array}$ & $\begin{array}{c}\text { Quantidade total de } \\
\text { aflatoxina }(\mu \mathrm{g}) \text { em } \\
\text { cada tipo de grão }\end{array}$ & $\begin{array}{c}\text { Participação da } \\
\text { contaminação } \\
\text { no lote }(\%)\end{array}$ \\
\hline Mofado & 891,30 & 4,42 & 1.154 & $1.028,56$ & 78,45 \\
Brotado & 419,00 & 2,08 & 256 & 107,26 & 8,18 \\
Ardido & $1.429,61$ & 7,09 & 38 & 54,33 & 4,14 \\
Imaturo & 608,10 & 3,02 & 56 & 34,05 & 2,60 \\
Chocho & 63,30 & 0,31 & 7 & 0,44 & 0,03 \\
Danificado & $5.231,76$ & 25,94 & 16 & 83,71 & 6,38 \\
Peliculado & $9.790,00$ & 48,55 & 0 & 0,00 & 0,00 \\
Quebrado & 451,48 & 2,24 & 0 & 0,00 & 0,00 \\
Despeliculado & 555,21 & 2,75 & 5 & 2,78 & 0,21 \\
Impurezas & 726,60 & 3,60 & - & $1.311,13$ & - \\
\hline Total & $20.166,36$ & 100,00 & 1.532 & & 100,00 \\
\hline
\end{tabular}


Os lotes de amendoim utilizados neste trabalho, embora destinados à extração de óleo, não seriam classificados nem como sendo do subgrupo industrial, de acordo com Brasil (1987), pois apresentaram percentagens de impurezas, grãos mofados, ardidos e demais defeitos superiores a 2, 8 e 20\%, respectivamente. Segundo a classificação oficial, o tipo industrial deveria apresentar no mínimo $70 \%$ de grãos peliculados. Entretanto, nas amostras dos lotes trabalhados, uma grande quantidade de grãos apresentava-se infestada por insetos, aumentando com isso, a percentagem de grãos danificados, resultando, como conseqüência, numa baixa percentagem de grãos peliculados (média de 38,96\%). Observou-se, também, que o tipo peliculado, que é o de principal interesse e o mais utilizado pela indústria, contribuiu em média com apenas $2,73 \%$ da contaminação por aflatoxinas do lote, apesar de estar com níveis acima do limite permitido pela legislação brasileira. Deste modo acredita-se que, aplicando-se a técnica da eliminação dos grãos mofados, brotados, ardidos, imaturos e chochos em lotes que possam ser enquadrados dentro da classificação do Ministério, os grãos restantes possam ser de alta qualidade e com nenhum ou baixo nível de aflatoxinas, como já comentado por Banes (1966), Bockelée-Morvan \& Gillier (1974) e Cole (1989b). 


\section{CONCLUSÕES}

- No presente estudo, em ordem decrescente de contaminação com aflatoxinas estão os tipos mofado, brotado, ardido, imaturo, chocho, danificado, peliculado, quebrado e despeliculado.

- No lotes estudados os tipos de grãos que, em peso, mais contribuiram para a contaminação do lote foram mofado $(55,04 \%)$, ardido $(19,17 \%)$, danificado $(9,6 \%)$ e brotado $(8,49 \%)$.

- A retirada dos grãos mof́ados, brotados, ardidos e danificados pode diminuir consideravelmente a contaminação do lote e poderá tornar-se viável economicamente, se o lote não estiver altamente contaminado. 


\section{REFERÊNCIAS BIBLIOGRÁFICAS}

AGRIANUAL-1996, p. 134-136., 1996.

AMARAL, L.S. Torta de amendoim e morte de suínos. O Biológico, v.27, p. 63, 1961.

BANES, D. Mycotoxins as a food problem. Cereal Science Today, v.11, n.1, p. 4-6, 1966.

BLANKENSHIP, P.D.; HOLADAY, C.E.; BUTLER, J.L. Some results concerning the occurence of aflatoxin in selected sizes of peanut kernels. Proceedings of the American Peanut Research and Education Association, v.5, p. 160-163, 1973. /Resumo em MEHAN, V.K.; McDONALD, D.; HARAVU, L.J.; JAYANTHI, S. The groundnut problem: review and literature database. Patancheru: International Crops Research Institute for the Semi-Arid Tropics, 1991. p. 154.I

BOCKELÉE-MORVAN; GILLIER, P. Trial of the elimination of aflatoxin in groundnuts by physical methods. Oléagineux, v.29, n.11, p. 513-516, 1974.

BRASIL. Ministério da Agricultura. Regras para análise de sementes. Brasília, Departamento Nacional de Produção Vegetal, 1976. 188 p. 
BRASIL. Leis, decretos. etc. Resolução no $34 / 76$ da Comissão Nacional de Normas e Padrões para Alimentos. Diário Oficial, Brasília, 19 jan. 1977. Seção I, pt. I, p.710.

BRASIL. Leis, decretos, etc. Ministério da Agricultura. Portaria número 329, Diário Oficial, Brasília, 30 dez. 1981.

BRASIL. Ministério da Agricultura. Normas de identidade, qualidade, embalagem e marcação do amendoim. Brasília, Comissão Técnica de Normas e Padrões, 1987. 24 p.

BRASIL. Leis, decretos. etc. Ministério da Agricultura. Portaria $n^{\circ}$ 183, 21 de março de 1996. Diário Oficial, Brasília, 25 mar. 1996.

CHIOU, R.Y.-Y.; WU, P.-Y.; YEN, Y.-H. Color sorting of lightly roasted and deskinned peanut kernels to diminish aflatoxin contamination in commercial lots. Journal of Agriculture and Food Chemistry, v.42, n.10, p. 21562160, 1994.

COLE, R.J. Preharvest aflatoxin in peanuts. International Biodeterioration, v. 25 , n. 4 , p. 253-257, 1989 a.

COLE, R.J. Technology of aflatoxin decontamination. In: INTERNATIONAL IUPAC SYMPOSIUM ON MYCOTOXINS AND PHYCOTOXINS, 7., Tokyo, 1988. Mycotoxins and phycotoxins'88: proceedings. Amsterdan: Elsevier Science, 1989b. p.177-184. (Bioactive Molecules, 10).

CUCULLU, A. F.; LEE, L. S.; MAYNE, R.; GOLDBLATT, L.A. Determination of aflatoxins in individual peanuts and peanut sections. Journal of the American Oil Chemists' Society, v. 43, p. 89-92, 1966. 
DICKENS, J.W. Aflatoxin occurrence and control during growth, harvest and storage of peanuts. In: RODRICKS, J. V.; HESSELTINE, C.W.; MEHLMAN, M.A. Mycotoxins in human and animal health. Park Forest South: Pathox Publ., 1977. p. 99-105.

DICKENS, J.W. ; WHITAKER, T.B. Efficacy of electronic color sorting and hand picking to remove aflatoxin contaminated kernels from commercial lots of shelled peanuts. Peanut Science, v.2, n.2, p. 45-50, 1975. IResumo em MEHAN, V.K.; McDONALD, D.; HARAVU, L.J.; JAYANTHI, S. The groundnut problem: review and literature database. Patancheru: International Crops Research Institute for the Semi-Arid Tropics, 1991. p. 340.1

DIENER, U.L. The mycoflora of peanuts in storage. Phytopathology, v.50, p. 220-223, 1960.

DIENER, U.L.; DAVIS, N.D. Aflatoxin production by isolates of Aspergillus flavus. Phytopathology, v.56, p. 1390-1393, 1966.

DIENER, U.L.; DAVIS, N.D. Limiting temperature and relative humidity for growth and production of aflatoxin and free fatty acids by Aspergillus flavus in sterile peanuts. Journal of the American Oil Chemists' Society, v.44, n.4, p. 259-263, 1967.

DIENER, U.L.; DAVIS, N.D. Aflatoxin formation by Aspergillus flavus. In: GOLDBLATT, L.A. Aflatoxin: scientific background, control, and implications. New York: Academic Press, 1969a. cap. 2, p. 13-54. 
DIENER, U.L.; DAVIS, N.D. Production of aflatoxin in peanuts under controlled environments. Journal of Stored Products Research, v.5, p. 251-258, 1969b. IResumo em MEHAN, V.K.; MCDONALD, D.; HARAVU, L.J.; JAYANTHI, S. The groundnut aflatoxin problem: review and literature database. Patancheru: ICRISAT, 1991. p. 132.I

DIENER, U.L.; COLE, R.J.; SANDERS, T.H.; PAYNE, G.A.; LEE, L.S.; KLICH, M.A. Epidemiology of aflatoxin formation by Aspergillus flavus. Annual Review of Phytopathogy, v.25, p. 249-270, 1987.

DOLLER, F.G. Detoxification of aflatoxins in food and feeds. In: GOLDBLATT, L.A. Aflatoxin: scientific background, control, and implications. New York: Academic Press, 1969. cap. 8, p. 359-392.

FAO. Sampling plans for aflatoxin analysis in peanuts and corn. Rome: FAO, 1993. 20p. (FAO-Food and Nutrition Paper, 55).

FAO QUARTERLY BULLETIN OF STATISTICS, v.8, n.3/4, p. 48, 1995.

FONSECA, H. Contribuição ao estudo da ocorrência de aflatoxina em tortas, farelos e farinhas de amendoim (Arachis hypogaea L.) no Estado de São Paulo. Anais da Escola Superior de Agricultura "Luiz de Queiroz", v. 25, p. $47-49,1968$.

FONSECA, H. Ocorrência de aflatoxina em farelos de amendoim (Arachis hypogaea L.) na Região Noroeste do Estado de São Paulo. Anais da Escola Superior de Agricultura "Luiz de Queiroz", v.30, p. 387-402, 1973a. 
FONSECA, H. Ocorrência de aflatoxina em farelos de amendoim (Arachis hypogaea L.) na Região Paulista Nova do Estado de São Paulo. Anais da Escola Superior de Agricultura "Luiz de Queiroz", v.30, p. 403-422, 1973b.

FONSECA, H. Ocorrência de aflatoxina em farelos de amendoim (Arachis hypogaea L.) na Região Sorocabana do Estado de São Paulo. Anais da Escola Superior de Agricultura "Luiz de Queiroz", v.30, p. 423-439, 1973c.

FONSECA, H. Ocorrência de aflatoxina em farelos de amendoim (Arachis hypogaea L.) na Região Araraquarense do Estado de São Paulo. Anais da Escola Superior de Agricultura "Luiz de Queiroz", v.32, p. 7-19, 1975.

FONSECA, H. Estudo da aflatoxina no amendoim da colheita à industrialização, na Região de Matão, São Paulo. Anais da Escola Superior de Agricultura "Luiz de Queiroz", v.33 p. 365-374, 1976a.

FONSECA, H. Estudo da aflatoxina no amendoim da colheita à industrialização, na Região de Monte Alto, São Paulo. Anais da Escola Superior de Agricultura "Luiz de Queiroz", v.33, p. 375-384, 1976b.

FONSECA, H. Estudo da aflatoxina no amendoim da colheita à industrialização, na Região de Santa Adélia, São Paulo. Anais da Escola Superior de Agricultura "Luiz de Queiroz", v.33, p. 385-394, 1976c.

FONSECA, H. Estudo da aflatoxina no amendoim da colheita à industrialização, na Região de Fernandópolis, São Paulo. Anais da Escola Superior de Agricultura "Luiz de Queiroz", v.33, p. 395-405, 1976d. 
FONSECA, H. ; NOGUEIRA, J.N.; GRANER, M. OLIVEIRA, A.J.; CARUSO, J.G.B.; BORALLI, C.; CALORI, M.A.; KHATOUNIAN, C.A. Natural ocurrence of mycotoxins in some brazilian foods. Part I. In: INTERNATIONAL IUPAC SYMPOSIUM ON MYCOTOXINS AND PHYCOTOXINS, 5., Vienna, 1982. Proceedings. Geneve: World Health Organization, 1982. p. 76-79.

FONSECA, H.; NOGUEIRA, J.N.; GRANER, M.; OLIVEIRA, A.J.; CARUSO, J.G.B.; BORALLI, M.A.; CALORI, M.A.; KHATOUNIAN, C.A. Natural occurrence of mycotoxins in some Brazilian foods. Part II. In: WORLD CONGRESS OF FOOD SCIENCE AND TECHNOLOGY, 6., Dublin, 1983. Proceedings. Dublin: Boole Press, 1983. p. 53-54.

FONSECA, H.; VALARINI, I.; CALORI-DOMINGUES, M.A.; WETTSTEIN, A.E.G. Ocorrência de aflatoxinas em amendoim, no Estado de São Paulo, durante os anos de 1988 e 1989. Anais da Escola Superior de Agricultura "Luiz de Queiroz", v.48, p. 301-316, 1991.

GNANASEKHARAN, V.; CHINNAN, M.S. Density distributions of aflatoxincontaminated peanuts in naturally and laboratory infected seeds. Transactions of the ASAE, v.35, n.2, p. 631-637, 1992.

GOLDBLATT, L.A. Aflatoxin: scientific background, control, and implications. New York: Academic Press, 1969. p. 1-11: Introduction.

GOLDBLATT, L.A.; DOLLEAR, F.G. Detoxification of contaminated crops. In: RODRICKS, J. V.; HESSELTINE, C.W.; MEHLMAN, M.A. Mycotoxins in human and animal health. Park Forest South: Pathox Publ., 1977. p. 139-150. 
HENDERSON, J.C.; KREUTZER, S.H.; SCHMIDT, A.A.; SMITH, C.A.; HAGEN, W.R. Flotation separation of aflatoxin-contaminated grain or nuts. IResumo em MEHAN, V.K.; McDONALD, D.; HARAVU, L.J.; JAYANTHI, S. The groundnut problem: review and literature database. Patancheru: International Crops Research Institute for the Semi-Arid Tropics, 1991. p.341.I

HESSELTINE, C.W.; SHOTWELL, J.J.E.; STUBBLEFIELD, R.D. Aflatoxin formation by Aspergillus flavus. Bacteriological Review, v.30, p. 795-805, 1966.

HESSELTINE, C.W.; SORENSON, W.G.; SMITH, M. Taxonomic studies of the aflatoxin-producing strains in the Aspergillus flavus group. Mycologia, v.62, p. 123-132, 1970

HSIEH, D.P.H. The role of aflatoxin in human cancer. In: STEYN, P.S.; VLEGGAAR, R. (ed.) Mycotoxins and phycotoxins. Amsterdan: Elsevier, 1986. p. $447-54$.

HSIEH, D.P.H. Potential human health hazards of mycotoxins. In: INTERNATIONAL IUPAC SYMPOSIUM ON MYCOTOXINS AND PHYCOTOXINS, 7., Tokyo, 1988. Mycotoxins and phycotoxins '88: proceedings. Amsterdan: Elsevier Science, 1989. p.69-80. (Bioactive Molecules, 10).

HSIEH, D.P.H.; WONG, Z. A.; WONG, J.J.; MICHAS, C.; RUEBNER, B.H. Comparative Metabolism of Aflatoxin. In: Rodricks, J.V.; HESSELTINE, C.W.; MEHLMAN, M.A. Mycotoxins in human and animal health. Park Forest South: Pathox Publ., 1977. p. 489-498. 
JACKSON, C.R. Influence of drying and harvesting procedures on fungus populations and aflatoxin production in peanut in Georgia. Phytopatholgy, v. 57, p. $458-462,1967$.

JARVIS, B. Factors affecting the production of mycotoxins. Journal of Applied Bacteriology, v.34, p. 199-213, 1971.

JELINEK, C.F. Distribution of mycotoxin - an analysis of world wide commodities data, including data from $\mathrm{FAO}$ /WHO/UNEP food contamination monitoring programme. In: INTERNATIONAL CONFERENCE ON MYCOTOXINS, 2., Bangkok, 1987. Rome: FAO/WHO/UNEP, 1988. p. 49.

KENSLER, C.J.; NATOLI, D.J. Processing to ensure wholesome products. in: GOLDBLATT, L.A. Aflatoxin: scientific background, control, and implications. New York: Academic Press, 1969. cap. 7, p. 334-353.

KIRKSEY, J.W.; COLE, R.J.; DORNER, J.W. Relationship between aflatoxin content and buoyancy of florunner peanut kernels. Peanut Science, v.16, p.48-51, 1989. IResumo em MEHAN, V.K.; McDONALD, D.; HARAVU, L.J.; JAYANTHI, S. The groundnut problem: review and literature database. Patancheru International Crops Research Institute for the Semi-Arid Tropics, 1991. p. $341 . /$

KIRKSEY, J.W.; COLE, R.J.; DORNER, J.W.; HENNING, R.J. Density segregation of peanuts naturally contaminated with aflatoxin. Proceedings of the American Peanut Research and Education Society, v.19, p. 36, 1987. IResumo em MEHAN, V.K.; McDONALD, D.; HARAVU, L.J.; JAYANTHI, S. The groundnut problem: review and literature database. Patancheru: International Crops Research Institute for the Semi-Arid Tropics, 1991. p. 341.I 
MENEZES, T.J.S.; TANGO, J.S.; COELHO, F.A.S., TEIXEIRA, C.G. Ocorrência de Aspergillus flavus e da aflatoxina em sementes, tortas e farelos de amendoim. Coletânea do Instituto de Tecnologia de Alimentos, v.1, p. 559-566, 1965/66.

MORAES, G.W.G. Estudos sobre aflatoxina. II. Extração e identificação de aflatoxina no farelo de amendoim. Arquivos da Escola de Veterinária, v. 16, p. 319-323, 1964.

MYCOTOXINS; economic and health risks. Ames: Council for Agricultural Science and Technology, 1989. 91p. (Task Force Report, 116).

NORTHOLT, M.D.; VERHULSDONK, C.A.H.; SOENTORO, P.S.S.; PAULSCH, W.E. Effect of water activity and temperature on aflatoxin production by Aspergillus parasiticus. Journal of Milk Food Technology, v.39, p. 170$174,1976$.

ORGANIZACION PANAMERICANA DE LA SALUD. Micotoxinas. México, 1983. 131p. (Publicación Científica, 453).

PARK, D.L. ; STOLOFF, L. Aflatoxin control how a regulatory agency managed risk from an unavoidable natural toxicant in food e feed. Regulatory Toxicology and Pharmacology, v.9, 109-30. 1989.

PATTERSON, D.S. Metabolism as a factor in determining the toxic action of the aflatoxin in different animal species. Food Cosmetics Toxicology, v. 11, p. 287-294, 1973. 
PELLETIER, M.J.; REIZNER, J.R. Comparison of fluorescence sorting and color sorting for the removal of aflatoxin from large groups of peanuts. Peanut Science, v.19, n. 1, p.15-20, 1992.

PETTIT, R.E. \& GEIGER, R.L. Dielectric properties of mold and mycotoxin damaged peanuts. Phytopathology, v.71, n. 2, p. 249, 1981.

PONS Jr., W.A.; CUCULLU, A.F.; LEE, L.S.; ROBERTSON, J.A.; FRANZ Jr., A. O.; GOLDBLATT, L.A. Determination of aflatoxin in agricultural products: use of aqueolis acetone for extraction. Journal of the Association of the Official American Chemists, v.49, n.3, p. 554-562, 1966.

PRADO, G. Incidência de aflatoxina B1 em alimentos. Revista de Farmácia e Bioquímica, v.5, n.2, p. 147-157, 1983.

PRADO, G. ; MATTOS, S.V.M.; PEREIRA, E.C. Niveis de aflatoxinas em alguns alimentos consumidos em Belo Horizonte no período de 1983 a 1988. Ciência e Tecnologia de Alimentos, v.9, p. 138-147, 1989.

RAIMO, H.F.; CORREA, R.; ANDRADE, R.M. Ação tóxica de farelo de torta de amendoim, produzido em São Paulo, para aves e outros animais. Boletim da Indústria Avícola, v.20, p. 361-364, 1962.

RAPER, K. V.; FENNELL, D. J. The genus Aspergillus. Baltimore: Willians \& Wilkins, 1965. 86p.

RICCIARD, J.A.; FERREIRA, J.F. Dosagem de aflatoxina $B_{1}$ em amendoim e em doces de amendoim. Revista Brasileira de Farmácia, v.67, p. 111117, 1986. 
SAAD, A.M.; ABDELGADIR, A.M.; MOSS, M.O. Exposure of infants to aflatoxin $M_{1}$ from mothers' breast milk in Abu Dhabi, UAE. Food Aditives and Contaminants, v.12, n.2, p. 255-261, 1995.

SABINO, M.; ZORZETTO, M.A.P.; PEDROSO, M.O.; MILANEZ, T.V. Incidência de aflatoxinas em amendoim e produtos derivados consumidos na cidade de São Paulo, no período de 1980 a 1987. Revista do Instituto Adolfo Lutz, v.49, p. 41-44, 1989.

SABINO, M.; ZORZETTO, M.A.P.; LAMARDO, L.C.A.; INOMATA, E.I; NAVAS, S.A.; MILANEZ, T.V. A survey of the occurrance of aflatoxins in peanuts and peanuts products in São Paulo state/Brazil in 1994. In: INTERNATIONAL IUPAC SYMPOSIUM ON MYCOTOXINS AND PHYCOTOXINS, 9., Rome, 1996. Rome, 1996. p.129.

SCHINDLER, A.F.; PALMER, J.G.; EISENBERG, W.V. Aflatoxin production by Aspergillus flavus as related to various temperatures. Applied Microbiology, v.15, n.5, p. 1006-1009, 1967.

SCHMIDT, F.R.; ESSER, K. Aflatoxins: medical, economic impact, and prospects for control. Process Biochemistry, v.20, p. 167-173, 1985.

SCHROEDER, H.W.; HEIN Jr, H. Aflatoxins: production of the toxins in vitro in relation to temperature. Applied Microbiology, v.15, n.2, p. 441-445, 1967.

SCOTT, P.M. Natural poisons. In: ASSOCIATION OF THE OFFICIAL ANALYTICAL CHEMISTS. Official methods of analysis. 15. ed. Arlington, 1990. cap.49, p. 1184-1213. 
SCUSSEL, V.M.; RODRIGUEZ-AMAYA, D.B. Teores de aflatoxinas em amendoim e seus produtos comercializados em Campinas em 1980-82. Boletim da Sociedade Brasileira de Ciência e Tecnologia de Alimentos, v.19, p. 109-119, 1985.

SHANK, R. Mycotoxicoses of man: dietary and epidemiological conditions. In: WYLLIE, T.D.; MOREHOUSE, L. (ed.). Mycotoxic fungi: mycotoxins, mycotoxicoses. New York: Marcel Dekker, 1978. v. 3, p.1-15.

SMITH, J.E.; MOSS, M.O. Mycotoxins: formation, analysis and significance. Chichester: John Wiley \& Sons, 1985. cap. 6: Natural ocurrence of mycotoxins, p. 83-103.

TANGO, J.S.; MENEZES, T.J.B.; TEIXEIRA, C.G. Levantamento da ocorrência de aflatoxina em sementes de amendoim das safras das águas e da seca. Coletânea do Instituto de Tecnologia de Alimentos, v.1, p. 1-11, $1965 / 66$.

TIEMSTRA, P.J. Aflatoxin control during food processing of peanuts. In: RODRICKS, J. V.; HESSELTINE, C.W.; MEHLMAN, M.A. Mycotoxins in human and animal health. Park Forest South: Pathox Publ., 1977. p. 120-137.

VELASCO, J.; MORRIS, S.L. Use of water slurries in aflatoxin analysis. Journal of Agricultural and Food Chemistry, v.24, n.1, p. 86-88, 1976.

WHITAKER, T.B.; WISER, E.H. Theoretical investigations into the accuracy of sampling shelled peanuts for aflatoxin. Journal of the American Oil Chemists' Society, v.46, p. 377-379, 1969. 
WORLD HEALTH ORGANIZATION. Mycotoxins. Geneve: WHO, 1979. 127p. (Environmental Health Criteria, 11). 